\title{
Supported Ag Nanoparticles and Clusters for CO Oxidation: Size Effects and Influence of the Silver-Oxygen Interactions
}

\author{
Maximilian Lamoth, ${ }^{\dagger}$ Milivoj Plodinec, ${ }^{\dagger,}$ Ludwig Scharfenberg, ${ }^{\S}$ Sabine Wrabetz, ${ }^{\dagger}$ Frank Girgsdies, \\ Travis Jones, ${ }^{\dagger}$ Frank Rosowski, ${ }^{\|, \perp}$ Raimund Horn, ${ }^{\S}$ Robert Schlögl, ${ }^{\dagger, \#}$ and Elias Frei ${ }^{*}, \dagger(0)$ \\ ${ }^{\dagger}$ Department of Inorganic Chemistry, Fritz Haber Institute of the Max Planck Society, 14195 Berlin, Germany \\ ${ }^{\ddagger}$ Division of Materials Physics, Rudjer Boskovic Institute, 10001 Zagreb, Croatia \\ ${ }^{\S}$ Department for Chemical Reaction Engineering, Technical University Hamburg-Harburg, 21073 Hamburg, Germany \\ "BasCat-UniCat BASF Joint Lab, Technical University Berlin, 10623 Berlin, Germany \\ ${ }^{\perp}$ Process Research and Chemical Engineering, Process Catalysis Research, BASF SE, 67056 Ludwigshafen, Germany \\ \# Department Heterogeneous Reactions, Max Planck Institute for Chemical Energy Conversion, 45470 Mülheim an der Ruhr, \\ Germany
}

\section{Supporting Information}

ABSTRACT: Supported Ag catalysts on silica and corundum have been synthesized applying an improved impregnation technique. The resulting Ag particle sizes can be divided into three categories concerning: (I) bulk-like, (II) nanoparticles of 1-6 nm, and (III) in situ created Ag clusters below $1 \mathrm{~nm}$. Ag nanoparticles and bulk-like $\mathrm{Ag}$ are investigated concerning their pretreatment dependence for $\mathrm{CO}$ oxidation showing that harsher pretreatment conditions need to be applied for smaller particle sizes, based on their tendency to form $\mathrm{Ag}_{2} \mathrm{CO}_{3}$. A particle size effect for $\mathrm{Ag}$ in oxidation reactions is investigated using $\mathrm{CO}$ oxidation as a test reaction. The $\mathrm{CO}$ oxidation performance is increasing with decreasing

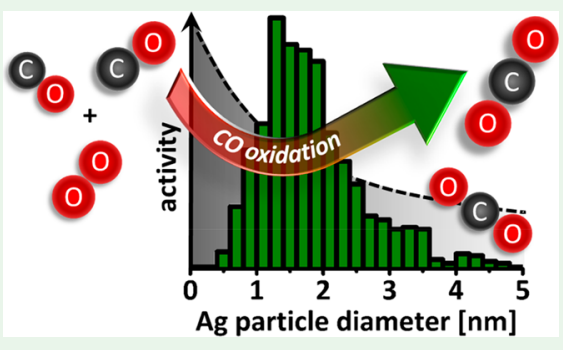
particle size with Ag clusters showing the highest activity. A novel method based on the adsorption of ethylene $\left(\mathrm{C}_{2} \mathrm{H}_{4}\right)$ as sensor molecule is further used to discriminate the silver-oxygen $(\mathrm{Ag}-\mathrm{O})$ interaction strength of bulk-like $\mathrm{Ag}, \mathrm{Ag}$ nanoparticles, and $\mathrm{Ag}$ clusters, showing a distinct $\mathrm{Ag}-\mathrm{O}$ chemistry for the three individual particle size regimes. By application of $\mathrm{C}_{2} \mathrm{H}_{4}$ breakthrough curve measurements, the available $\mathrm{Ag}$ surface area is determined which enables a correlation of $\mathrm{Ag}$ surface area and $\mathrm{CO}$ oxidation rate. Correlations of $\mathrm{Ag}-\mathrm{O}$ interaction strength, $\mathrm{Ag}$ surface area, and $\mathrm{CO}$ oxidation activity are discussed within the scope of this work.

KEYWORDS: Ag nanoparticles/clusters, CO oxidation, Ag-oxygen interaction, apparent Ag surface area, size effect

\section{INTRODUCTION}

Supported Ag catalysts are used in several oxidation reactions such as of carbon monoxide ${ }^{1}$ and methanol $^{2}$ or epoxidation of ethylene $^{3}$ and propene. ${ }^{4}$ Since $\mathrm{Ag}$ is generally applied in a broad particle size (PS) regime, reliable studies on a Ag PS effect are rare. The investigation of PS effects in catalysis is significantly important since they can influence the catalyst's activity and selectivity due to changes in chemical characteristics caused by quantum-confinement effects for very small particles of only a few nanometers. ${ }^{5-9}$ For the ethylene epoxidation reaction the influence of $\mathrm{Ag}$ PS in the regime of roughly $10-200 \mathrm{~nm}$ has already been well investigated with an overall consent that increasing Ag PS up to around 50-80 nm leads to more active but equally selective catalysts and that nanoparticles below $10 \mathrm{~nm}$ show a suppressed or decreased catalytic activity, following a volcano-type behavior. ${ }^{5-7,10-14}$ Only a limited number of studies were so far able to investigate the Ag PS regime of $<10 \mathrm{~nm}$ concerning their catalytic activity in ethylene epoxidation, ${ }^{15}$ propylene epoxidation, ${ }^{16}$ carbon monoxide oxidation, ${ }^{17}$ or the interaction of Ag with oxygen ${ }^{18}$ and various oxide support surfaces. ${ }^{19,20}$ However, so far the results allow no clear conclusion whether Ag nanoparticles are more or less active in oxidation reactions when decreasing its size down to a few nanometers or cluster size. In addition, the debate is influenced by the complex and unique chemistry of Ag and oxygen. ${ }^{21-25}$

The unique character of Ag compared to other metals is reasoned in the activation of oxygen on the surface and subsurface, while stable oxide phases at elevated temperatures and atmospheric pressure ${ }^{26}$ are absent. This intriguing surface and subsurface silver-oxygen $(\mathrm{Ag}-\mathrm{O})$ chemistry explains why, for example, for the ethylene epoxidation reaction exclusively supported Ag catalysts are used. Further, a large variety of oxygen species like atomic, molecular, strongly bound, ionic, covalent, surface, subsurface, near defects, bulk-dissolved, or surface-embedded oxygen have already been described and are

Received: February 26, 2019

Accepted: April 10, 2019

Published: April 10, 2019 
still under debate. ${ }^{27,28}$ Nevertheless, most of these findings are made on single crystals, foils, or powders, ${ }^{23,29-31}$ since the synthesis and investigation of small and stabilized $\mathrm{Ag}$ nanoparticles are challenging. ${ }^{32,33}$

The synthesis of well-defined small Ag nanoparticles with a narrow size distribution can be regarded as the first step to reliably facilitate PS effect investigations. Crucial parameters are the properties of the support material and the precursor material for Ag. For the suitability of the support, the specific surface area, structural stability, and number and nature of functional groups are important. Sticking to the partial oxidation reaction of ethylene, a feature of the desired product ethylene epoxide is its high sensitivity to especially Lewis acidic groups on the support surface. ${ }^{34}$ This already limits the number of possible supports, with corundum $\left(\alpha-\mathrm{Al}_{2} \mathrm{O}_{3}\right)$ and silica $\left(\mathrm{SiO}_{2}\right)$ as most promising candidates. ${ }^{35}$ Besides, the low surface acidity of $\alpha-\mathrm{Al}_{2} \mathrm{O}_{3}$ is based on the overall low number of functional groups due to its low specific surface area of usually $<5 \mathrm{~m}^{2} \cdot \mathrm{g}^{-1} \cdot{ }^{36}$ For a successful synthesis and stabilization of nanoparticles, however, high surface area supports are needed. The necessary chemical inertness of the supports also limits the use of metal-support interactions, which is a common strategy for metal nanoparticle stabilization. ${ }^{37-41}$ Flame hydrolyzed silica exhibits a high concentration of surface OH-groups paired with a high hydrophilicity, a moderate surface acidity, and high structural as well as textural stability and is therefore identified as suitable support material for the synthesis of small nanoparticles and applied as support material in this work.

As precursor materials, among Ag carbonates, sulfates, acetates, oxalates, lactates, succinates, glycolates, and multiple amine systems, ${ }^{42,43} \mathrm{Ag}$ nitrate $\left(\mathrm{AgNO}_{3}\right)$ offers the useful ability of melting at $210{ }^{\circ} \mathrm{C}$ before its decomposition at $440{ }^{\circ} \mathrm{C}$. ${ }^{44}$ This enables a rather controlled development of $\mathrm{Ag}$ nanoparticles by thermal treatments. Additionally, $\mathrm{AgNO}_{3}$ dissolves easily in water, thus being a suitable impregnation solution for hydrophilic silica. The $\mathrm{OH}$-group rich surface of $\mathrm{SiO}_{2}$ enables $\mathrm{Ag}^{+}$ions to undergo ion exchange reactions, ${ }^{45}$ thereby being distributed and stabilized over the complete support surface area leading to metallic nanoparticles of $<6 \mathrm{~nm}$, which was, to the best of our knowledge, so far only achieved on very acidic and porous supports like zeolites. ${ }^{46}$ Furthermore, a partial calcination can be used to in situ create Ag clusters during reaction conditions, which represents a novel approach in the course of the presented research.

In summary, the present work deals for the first time with the investigation of the $\mathrm{Ag}-\mathrm{O}$ chemistry for a series of silica supported Ag catalysts with solely Ag nanoparticles of $<6 \mathrm{~nm}$ down to cluster sized Ag. All samples were thoroughly analyzed by multiple techniques including powder X-ray diffraction (PXRD), thermogravimetric analysis (TGA) coupled to evolved gas analysis (EGA), inductive coupled plasma optical emission spectroscopy (ICP-OES), scanning electron microscopy with energy dispersive X-ray detection (SEM/EDX), and transmission electron microscopy (TEM). We apply the oxidation of carbon monoxide as a test reaction for the activation of oxygen ${ }^{47}$ and a combination of microcalorimetry and ethylene adsorption (as probe molecule) for a qualitative and quantitative assessment of the $\mathrm{Ag}-\mathrm{O}$ interaction. For comparison reasons, a conventional $\mathrm{Ag} / \alpha-\mathrm{Al}_{2} \mathrm{O}_{3}$ sample is analyzed.

\section{EXPERIMENTAL SECTION}

Synthesis of $\mathrm{Ag} / \mathrm{SiO}_{2}$ and $\mathrm{Ag} / \boldsymbol{\alpha}-\mathrm{Al}_{2} \mathrm{O}_{3}$. For the silica supported catalysts $\mathrm{SiO}_{2}$ (Aerosil 300, Degussa, hydrophilic fumed silica powder, primary particles: spherical, 7-40 nm, no porosity) was transferred into a round-bottom flask. The flask was attached to a vacuum evaporator, which was modified to a dedicated impregnation setup to achieve a controlled distribution on the support under low vacuum. The support was subsequently outgassed under a pressure of $60 \mathrm{mbar}$ at room temperature for $10 \mathrm{~min}$, followed by impregnation under 60 mbar under constant stirring and rotation of the flask. Aqueous $\mathrm{AgNO}_{3}\left(\mathrm{AgNO}_{3(\mathrm{aq})}\right)$ was used according to $5 \mathrm{wt} \% \mathrm{Ag}$ loading (labeled as $\mathrm{Ag} 5 / \mathrm{SiO}_{2}$ ) with a drop rate of 30 drops per minute. The impregnated support was dried for at least $12 \mathrm{~h}$ at $110^{\circ} \mathrm{C}$ in air. The dried material was pressed at $5 \times 10^{4} \mathrm{~N} \cdot \mathrm{cm}^{-2}$ for 1 min and transferred into a $100-200 \mu \mathrm{m}$ sieve fraction. The subsequent calcination was performed in a rotating tube furnace with a constant flow of $21 \% \mathrm{O}_{2}$ in $\mathrm{Ar}\left(300 \mathrm{~mL} \cdot \mathrm{min}^{-1}\right)$ with a heating rate of $2{ }^{\circ} \mathrm{C}$. $\mathrm{min}^{-1}$ to $400-600{ }^{\circ} \mathrm{C}$ with $0-3 \mathrm{~h}$ dwell time, labeled as $X / Y$ with $X=$ temperature and $Y=$ dwell time. The sample was finally cooled down to room temperature under the same gas feed.

The amount of $\mathrm{H}_{2} \mathrm{O}$ needed for impregnation was determined by adding the exact amount for which no excess $\mathrm{H}_{2} \mathrm{O}$ was visible on the support and no clumping occurred. This volume is referred to as "solvent capacity volume" (SCV) and describes the amount of solvent needed to fill the pores and to cover the complete surface of the material. Thereby, it enables a good distribution of the solved $\mathrm{AgNO}_{3(\mathrm{aq})}$ over the available surface area of the support. In the case of $\mathrm{SiO}_{2}$ with a specific BET surface area of $328 \mathrm{~m}^{2} \cdot \mathrm{g}^{-1}$ the necessary amount of $\mathrm{H}_{2} \mathrm{O}$ to reach the $\mathrm{SCV}$ was determined to be $1.43 \mathrm{~mL} \cdot \mathrm{g}^{-1}$.

For the synthesis of a reference sample, $15.5 \mathrm{wt} \% \mathrm{Ag}$ was loaded on corundum $\left(\alpha-\mathrm{Al}_{2} \mathrm{O}_{3}\right)$ with a specific surface area of $\sim 1.0 \mathrm{~m}^{2} \cdot \mathrm{g}^{-1}$ using an $\mathrm{Ag}$ oxalate based precursor according to patent literature, ${ }^{36}$ labeled as $\mathrm{Ag} 15 / \alpha-\mathrm{Al}_{2} \mathrm{O}_{3}$. In short, a silver oxalate-ethylenediamine complex is synthesized by mixing oxalic acid dehydrate, ultrapure water, $\mathrm{KOH}$, and $\mathrm{AgNO}_{3}$ to form a silver oxalate complex which is subsequently reacted with the complexing agent ethylenediamine. The $\alpha-\mathrm{Al}_{2} \mathrm{O}_{3}$ support was then impregnated with the silver oxalateethylenediamine solution followed by a calcination under air.

CO oxidation was performed in a self-constructed catalytic reactor setup equipped with an online gas analyzer (X-STREAM XE, Emerson/Rosemount) with an infrared and a paramagnetic sensor, for the simultaneous quantification of oxygen, carbon monoxide, carbon dioxide and water. $\mathrm{CO}$ gas was purified using a carbonyl remover consisting of a tube filled with inert silicon carbide heated up to $300{ }^{\circ} \mathrm{C}$. He gas passed a water and oxygen filter patron (Air Liquide). A quartz plug-flow U-tube reactor was loaded with $30 \mathrm{mg}$ of the $\mathrm{Ag5} / \mathrm{SiO}_{2}$ catalyst (100-200 $\mu \mathrm{m}$ sieve fraction) diluted with 250 $\mathrm{mg}$ inert $\mathrm{SiC}(250-355 \mu \mathrm{m}$ sieve fraction) surrounded by about 40 $\mathrm{mg}$ of quartz wool on each side. In the case of $\mathrm{Ag} 15 / \alpha-\mathrm{Al}_{2} \mathrm{O}_{3}$ catalysts, 3 times more mass had to be loaded to reach the same catalyst volume and space velocity. $\mathrm{CO}$ oxidation was performed with 96 vol \% $\mathrm{He}, 2$ vol $\% \mathrm{CO}$, and 2 vol $\% \mathrm{O}_{2}$ at $100 \mathrm{~mL} \cdot \mathrm{min}^{-1}$. All samples were pretreated in $21 \% \mathrm{O}_{2}$ in $\mathrm{He}$ at a flow of $100 \mathrm{~mL} \cdot \mathrm{min}^{-1}$ at a certain temperature and dwell time. The catalytic oxidation was tested in a three-cycle test with heating to $250{ }^{\circ} \mathrm{C}$ with $2{ }^{\circ} \mathrm{C} \cdot \mathrm{min}^{-1}$ and cooling to $30{ }^{\circ} \mathrm{C}$ between each cycle. For excluding diffusion limitation effects, the samples are analyzed by comparing the temperatures for $10 \%$ CO conversion $\left(T_{10 \%}\right.$ or temperature $\left.X_{\mathrm{CO}, 10 \%}\right)$.

The reaction order was determined by pretreating the samples at $300{ }^{\circ} \mathrm{C}$ for $3 \mathrm{~h}$ in $21 \% \mathrm{O}_{2}$ in $\mathrm{He}$ and one subsequent $\mathrm{CO}$ cycle to 250 ${ }^{\circ} \mathrm{C}$. After that the samples were kept constantly at $100{ }^{\circ} \mathrm{C}$ with a variation of $\mathrm{O}_{2}$ or $\mathrm{CO}$ partial pressure.

Powder X-ray diffraction (PXRD) patterns were recorded using a Bruker AXS D8 Advance II Theta/Theta diffractometer in BraggBrentano geometry using $\mathrm{Ni}$ filtered $\mathrm{Cu} \mathrm{K} \alpha_{1+2}$ radiation and a position sensitive LynxEye silicon strip detector. The sample powder was filled into the recess of a cup-shaped sample holder, the surface of the powder bed being flush with the sample holder edge (front loading). The resulting diffractograms were analyzed by full pattern 
fitting using the TOPAS software ${ }^{48}$ to extract lattice parameters and crystallite sizes.

$\mathbf{N}_{2}$ physisorption was performed in a Quantochrome Autosorb-6-BMP machine after degassing a specific amount (500 mg for $\alpha-\mathrm{Al}_{2} \mathrm{O}_{3}$, $30 \mathrm{mg}$ for $\mathrm{SiO}_{2}$ ) of the sample at $150{ }^{\circ} \mathrm{C}$ for $15 \mathrm{~h}$. The resulting isotherms were recorded at the temperature of liquid nitrogen. Calculation of the surface area was performed according to the equation of Brunauer, Emmet, and Teller (BET equation). ${ }^{49}$

Thermogravimetric analysis/evolved gas analysis (TGA-EGA) was conducted using a STA 449 C Jupiter thermoanalyzer (Netzsch) under oxidative $\left(21 \% \mathrm{O}_{2}\right.$ in $\left.\mathrm{Ar}\right)$ or inert $(\mathrm{Ar})$ gas atmosphere with a total flow of $100 \mathrm{~mL} \cdot \mathrm{min}^{-1}$. The sample was heated up with $2{ }^{\circ} \mathrm{C}$. $\min ^{-1}$ to $500-600{ }^{\circ} \mathrm{C}$ without or with $1 \mathrm{~h}$ dwell time. The setup was connected to a quadrupole mass spectrometer (QMS200 Omnistar, Balzers) for evolved gas analysis via a quartz capillary heated to $40^{\circ} \mathrm{C}$. All data were analyzed using the Netzsch Proteus Thermal Analysis software package (version 6.10).

Scanning transmission electron microscopy (STEM) imaging was performed using a double Cs corrected JEM-ARM200CF (JEOL) operated at $200 \mathrm{kV}$ and equipped with $\mathrm{ADF}$ (annular dark-field) and BF (bright-field) detectors. Samples were prepared by direct deposition of dry powder onto a Quantifoil Au holey grid. For the resulting histograms, the diameter of 1000 particles was measured for each sample.

Scanning electron microscopy (SEM) was performed on a Hitachi S4800 equipped with a field emission gun and YAG-BSE (backscattered electrons) and energy dispersive X-ray (EDX) detectors. The system was operated at a working distance of $10 \mathrm{~mm}$ with $10 \mathrm{kV}$. $\mathrm{C}_{2} \mathrm{H}_{4}$ adsorption measurements were performed using a temporal analysis of products approach at atmospheric pressure (atmTAP) at $40{ }^{\circ} \mathrm{C}$ using breakthrough curve measurements with a high-speed transient reactor. ${ }^{50} \mathrm{~A}$ plug-flow reactor was loaded with a catalyst sample with a mass of $100 \mathrm{mg}$. The sample was pretreated at $300{ }^{\circ} \mathrm{C}$ for $3 \mathrm{~h}$ under a constant flow of $21 \%$ oxygen in $\mathrm{He}$, after which the reactor was cooled slowly to the desired temperature under the same gas flow. Before the $\mathrm{C}_{2} \mathrm{H}_{4}$ breakthrough curve was measured, the gas flow was first changed to pure $\mathrm{He}\left(100 \mathrm{~mL} \cdot \mathrm{min}^{-1}\right)$ to completely purge the gas-phase oxygen from the reactor. Then, the gas composition was instantly switched to 3.93 mbar of $\mathrm{C}_{2} \mathrm{H}_{4}$ in $\mathrm{He}$. Besides $\mathrm{C}_{2} \mathrm{H}_{4}$, a small fraction of Ar was also present in the feed in order to determine the mean reactor residence time of a nonadsorbing reference species. $\mathrm{C}_{2} \mathrm{H}_{4}$ and $\mathrm{Ar}$ concentrations at the reactor exit were monitored using a mass spectrometer. For each sample the adsorption measurement was repeated three times. Between those measurements, $\mathrm{C}_{2} \mathrm{H}_{4}$ was thoroughly desorbed by ramping the temperature to $230^{\circ} \mathrm{C}$ under $21 \% \mathrm{O}_{2}$ in $\mathrm{He}$ and subsequent cooling to $40{ }^{\circ} \mathrm{C}$.

Microcalorimetry was performed in a HT1000 (RT to $1000^{\circ} \mathrm{C}$ ) and MS70 (RT to $100{ }^{\circ} \mathrm{C}$ ) Tian-Calvet calorimeter (SETARAM) combined with a custom-designed high vacuum (HV) and gas dosing apparatus. The sample was placed in a batch reactor. $\mathrm{C}_{2} \mathrm{H}_{4}$ adsorption experiments were performed after cleaning the samples at $300{ }^{\circ} \mathrm{C}$ for $3 \mathrm{~h}$ in synthetic air $\left(200 \mathrm{mbar}^{\mathrm{O}_{2}}\right)$ or additional reduction by $\mathrm{CO}$ oxidation feed $\left(2 \% \mathrm{CO}, 2 \% \mathrm{O}_{2}\right)$ followed by stepwise dosing of around 0.01-4.00 mbar of $\mathrm{C}_{2} \mathrm{H}_{4}$ at $40{ }^{\circ} \mathrm{C}$. Prior to readsorption of $\mathrm{C}_{2} \mathrm{H}_{4}$ the sample was treated at $10^{-8}$ mbar to desorb reversible bound $\mathrm{C}_{2} \mathrm{H}_{4}$ and free $\mathrm{C}_{2} \mathrm{H}_{4}$ adsorption sites. Oxygen adsorption experiments were performed at $200{ }^{\circ} \mathrm{C}$ after (I) a pretreatment of $600{ }^{\circ} \mathrm{C}$ at $10^{-8}$ mbar for $1 \mathrm{~h}$ and (II) a proximate reduction at $400{ }^{\circ} \mathrm{C}$ for $1 \mathrm{~h}$ combined with 10 mbar $\mathrm{H}_{2}$.

Inductive coupled plasma optical emission spectroscopy (ICPOES) was used to determine the $\mathrm{Ag}$ loading of the catalysts. Therefore, the sample is solubilized using $\mathrm{LiF}$, nitric acid, and water at $230{ }^{\circ} \mathrm{C}$, diluted with water, and analyzed with a PerkinElmer ICP OES Optima 8300.

\section{RESULTS AND DISCUSSION}

Sample Preparation and Characterization. All samples were synthesized by impregnation following an incipient wetness approach, while the solvent capacity volume (SCV) was determined experimentally (for details see Experimental Section). For the impregnation, a modified vacuum evaporator was used. Benefits are the use of low vacuum $(60 \mathrm{mbar})$, rotation of the flask, and controlled addition of impregnation solution, all occurring in a closed system. This enables a superior distribution of the impregnation solution compared to conventional impregnation techniques. An important criterion for Ag nanoparticles with a narrow PS distribution is the properly chosen surface area of the support. Figure 1 shows

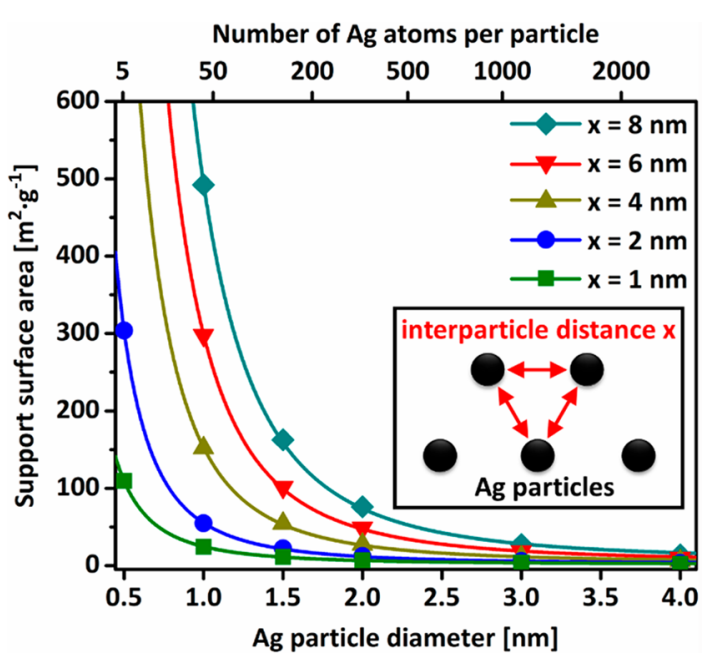

Figure 1. Required support surface area per gram support versus $\mathrm{Ag}$ nanoparticle size for different interparticle distances $x$ of $1,2,4,6$, and $8 \mathrm{~nm}$. Calculations were performed for $5 \mathrm{wt} \% \mathrm{Ag}$ loading, assuming no wetting.

representatively the ratio between the surface area, the PS of $\mathrm{Ag}$, and the interparticle distance, which determines the sintering stability of the formed particles (near the Ag support interaction) for a support loaded with $5 \mathrm{wt} \% \mathrm{Ag}$. It reveals that for a good stabilization of nanoparticles $<2 \mathrm{~nm}$ support surface areas of already a few hundred $\mathrm{m}^{2} \cdot \mathrm{g}^{-1}$ are necessary. For this reason hydrophilic flame hydrolyzed $\mathrm{SiO}_{2}$ was selected since it offers a suitable BET surface area of $328 \mathrm{~m}^{2} \cdot \mathrm{g}^{-1}$. Thereby, it theoretically enables the synthesis and stabilization of nanoparticles consisting of less than 200 atoms down to even small clusters that consist of less than $50 \mathrm{Ag}$ atoms.

In the following, the samples are named according to their $\mathrm{Ag}$ loading in wt \% and the chosen support, i.e., $5 \mathrm{wt} \% \mathrm{Ag}$ on silica as $\mathrm{Ag} 5 / \mathrm{SiO}_{2}$. Calcination conditions are labeled as $X / Y$ ( $X=$ temperature, $T$ in ${ }^{\circ} \mathrm{C}$, and $Y=$ dwell time, $t$ in h), i.e., $\mathrm{Ag} 5 / \mathrm{SiO}_{2} 400 / 1$ for a calcination at $400{ }^{\circ} \mathrm{C}$ with $1 \mathrm{~h}$ dwell time. Pretreatment conditions for catalytic or analytical tests are given with the same $T / t$ notation. An overview of relevant samples and their corresponding characteristics is given in Table 1 .

To identify proper calcination conditions, a $\mathrm{AgNO}_{3} / \mathrm{SiO}_{2}$ precursor was analyzed with TGA-EGA upon thermal treatment (Supporting Information, Figure S1A). After desorption of the physisorbed $\mathrm{H}_{2} \mathrm{O}$, a first $\mathrm{NO}$ release is detected at $160{ }^{\circ} \mathrm{C}$ with a $\mathrm{NO}$ evolution maximum at $220^{\circ} \mathrm{C}$, being in good agreement with reported $210{ }^{\circ} \mathrm{C}^{44}$ for the $\mathrm{AgNO}_{3}$ melting point. It is assumed that $\mathrm{AgNO}_{3}$ nanoislands are formed, which are size determining for the final $\mathrm{Ag}$ particles and clusters. Upon further calcination, $\mathrm{AgNO}_{3}$ decomposes to $\mathrm{Ag}^{0}$ which is again indicated by a strongly increased NO signal with an overall maximum at $390{ }^{\circ} \mathrm{C}$. The detected mass loss of 
Table 1. Overview of Investigated Ag (Pre-)Catalysts with Nominal (nom) and Experimentally (exp) Determined Ag Loading

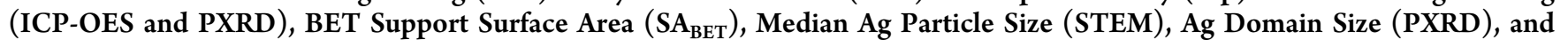
Internal FHI Number

\begin{tabular}{|c|c|c|c|c|c|c|c|}
\hline \multirow[b]{2}{*}{ sample } & \multirow[b]{2}{*}{ calc cond $\left[{ }^{\circ} \mathrm{C} / \mathrm{h}\right]$} & \multicolumn{2}{|c|}{ Ag loading [wt \%] } & \multirow[b]{2}{*}{ support $\mathrm{SA}_{\mathrm{BET}}\left[\mathrm{m}^{2} \cdot \mathrm{g}^{-1}\right]$} & \multirow[b]{2}{*}{ median Ag particle size $[\mathrm{nm}]$} & \multirow[b]{2}{*}{$\mathrm{Ag}$ domain size $[\mathrm{nm}]$} & \multirow[b]{2}{*}{ FHI no. } \\
\hline & & nom & $\exp$ & & & & \\
\hline $\mathrm{AgNO}_{3} / \mathrm{SiO}_{2}$ & & 5 & $4.3^{a}$ & 328 & 1.8 & $\mathrm{n} / \mathrm{a}$ & 27150 \\
\hline \multirow[t]{6}{*}{$\mathrm{Ag} 5 / \mathrm{SiO}_{2}$} & $400 / 1$ & 5 & & 328 & 2.0 & $\mathrm{n} / \mathrm{a}$ & 27127 \\
\hline & $400 / 3$ & & & & & $\mathrm{n} / \mathrm{a}$ & 27128 \\
\hline & $500 / 1$ & & & & 2.4 & $\mathrm{n} / \mathrm{a}$ & 27130 \\
\hline & $500 / 3$ & & & & & $\mathrm{n} / \mathrm{a}$ & 27131 \\
\hline & $600 / 1$ & & $4.5^{a}$ & & 2.3 & $6.1 \pm 0.9$ & 27133 \\
\hline & $600 / 3$ & & & & & $6.3 \pm 0.9$ & 27134 \\
\hline \multirow[t]{2}{*}{$\mathrm{Ag} 15 / \alpha-\mathrm{Al}_{2} \mathrm{O}_{3}$} & $280 / 0.2$ & 15.5 & $12.4^{a}$ & $\sim 1.0$ & $\sim 30$ and $\sim 200$ & 39.4 & 26630 \\
\hline & & & $14.0^{b}$ & & & & \\
\hline
\end{tabular}

${ }^{a}$ ICP-OES. ${ }^{b}$ PXRD full pattern fitting.

$3.33 \%$ during $\mathrm{NO}$ evolution $\left(\mathrm{m} / z=30,150-500{ }^{\circ} \mathrm{C}\right)$ is slightly higher than the theoretical weight loss of $2.87 \%$, explained by additional $\mathrm{H}_{2} \mathrm{O}$ evolution $(\mathrm{m} / z=18,25-465$ $\left.{ }^{\circ} \mathrm{C}\right)$.

On the basis of the TGA-EGA of differently calcined samples (Figure S1B), a remaining amount of $14 \% \mathrm{AgNO}_{3}$ is calculated after a calcination temperature of $400{ }^{\circ} \mathrm{C}$ without dwelling (400/0) and $6 \%$ for $400{ }^{\circ} \mathrm{C}$ for $1 \mathrm{~h}$ dwelling (400/1). At calcination temperatures of $500{ }^{\circ} \mathrm{C}$ and higher no remaining NO evolution was detected. On the basis of these results (TGA-EGA, Figure S1), a set of samples with three different calcination temperatures $\left(400,500\right.$, and $600{ }^{\circ} \mathrm{C}$ ) and two different dwell times $(1$ and $3 \mathrm{~h}$ ) at each temperature was synthesized. The comparably mild calcination temperature of $400{ }^{\circ} \mathrm{C}$ (with $6 \%$ residual $\mathrm{AgNO}_{3}$ ) is selected since any thermally induced sintering should be avoided.

Since all $\mathrm{Ag} 5 / \mathrm{SiO}_{2}$ samples are derived from the same precursor batch $\mathrm{AgNO}_{3} / \mathrm{SiO}_{2}$, they are expected to have the same Ag loading. For an experimental analysis of the $\mathrm{Ag}$ loading ICP-OES was performed. The Ag loading for the $\mathrm{AgNO}_{3} / \mathrm{SiO}_{2}$ precursor was determined to $4.3 \mathrm{wt} \%$. This result is in very good agreement with the determined $\mathrm{Ag}$ loading for sample $\mathrm{Ag} 5 / \mathrm{SiO}_{2}$ calcined at conditions of $600 / 1$ of $4.5 \mathrm{wt} \%$. Both values are thereby very near the nominal loading of $5 \mathrm{wt} \%$ and show that the calcination does not influence the Ag loading.

For an overview of the resulting Ag PS after impregnation and calcination, STEM analysis was performed for the $\mathrm{AgNO}_{3} /$ $\mathrm{SiO}_{2}$ precursor dried at $110{ }^{\circ} \mathrm{C}$ for $12 \mathrm{~h}$ without calcination and additionally $\mathrm{Ag} 5 / \mathrm{SiO}_{2}$ samples calcined at conditions of 400/1 and 600/1. After drying, the $\mathrm{AgNO}_{3} / \mathrm{SiO}_{2}$ already shows a uniform size distribution with Ag PS up to $4.6 \mathrm{~nm}$ and a median value of $1.8 \mathrm{~nm}$ (Figure 2A). Those nanoparticles show a $d$-spacing of the Ag 111 lattice plane of $2.40 \AA$ (Figure S2), being in good agreement with the literature value of 2.36 A. ${ }^{51}$ Besides, the inset of Figure $2 \mathrm{~A}$ shows single $\mathrm{Ag}$ atoms that are well distributed over the whole support surface, which are likely atomically dispersed $\mathrm{Ag}^{+}$species that formed after ionexchange reactions on the silica support. The occurrence of $\mathrm{Ag}$ nanoparticles after drying at comparably mild $110{ }^{\circ} \mathrm{C}$ might be explained by the instability of nitrates which decompose already below $160{ }^{\circ} \mathrm{C}$ (see Figure $2 \mathrm{~A}$ ) as a function of $12 \mathrm{~h}$ dwell time. A representative STEM image for sample Ag5/ $\mathrm{SiO}_{2} 400 / 1$ is shown in Figure 2B with the corresponding PS distribution (histogram). The $\mathrm{Ag}$ particles are well distributed over the support without atomic species visible and a median

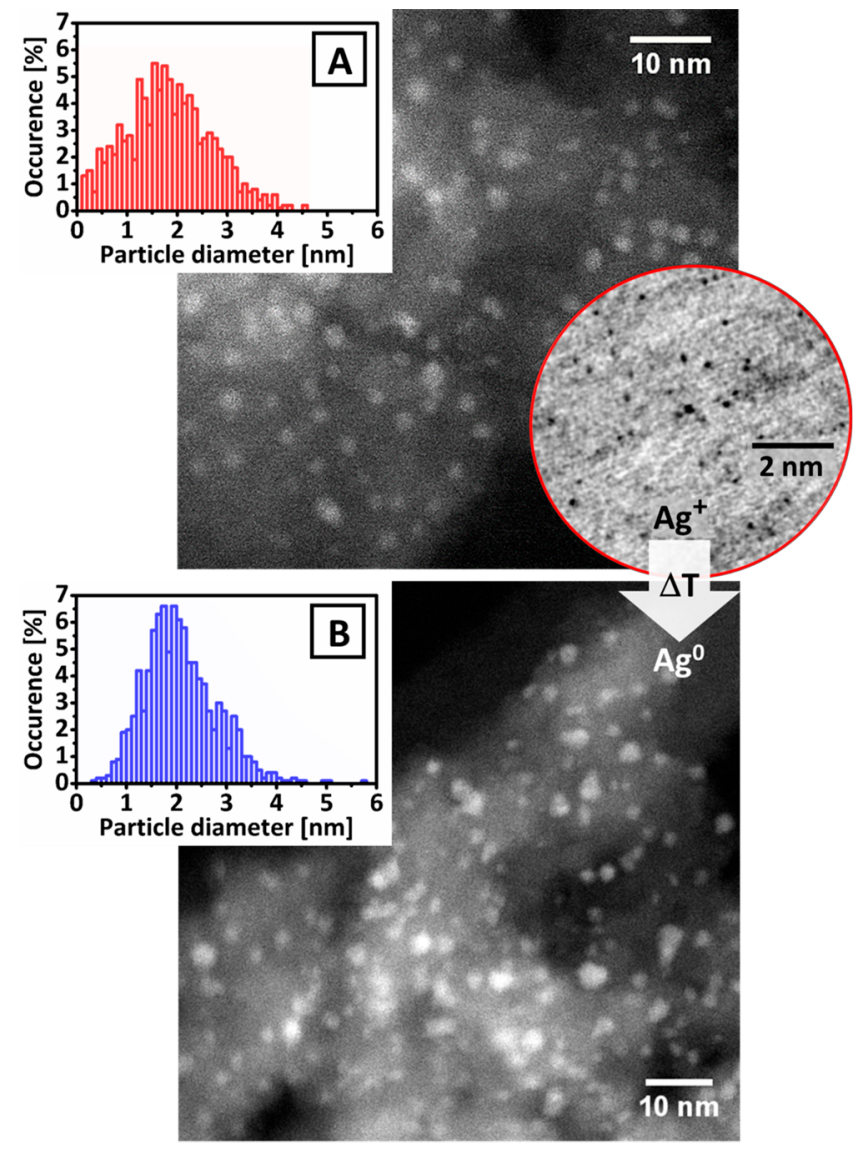

Figure 2. STEM ADF image of the catalyst precursor $\mathrm{AgNO}_{3} / \mathrm{SiO}_{2}$ (A). Inset of (A) shows a higher magnification image of the same sample, which was inverted and processed using a Gaussian blur (original image see Figure $\mathrm{S} 1$ ). $\mathrm{Ag} 5 / \mathrm{SiO}_{2}$ catalyst calcined at conditions of 400/1 is shown in (B). Bright spots correspond to $\mathrm{Ag}$ particles. PS distribution insets are shown on the top left.

PS of $2.0 \mathrm{~nm}$ (standard deviation $\mathrm{SD}=0.71 \mathrm{~nm}$ ). In comparison, the $\mathrm{Ag} 5 / \mathrm{SiO}_{2} 600 / 1$ sample exhibits a median PS of $2.3 \mathrm{~nm}(\mathrm{SD}=0.72 \mathrm{~nm}$; see Figure $6 \mathrm{~B})$. In addition, a very narrow size distribution is obtained without $\mathrm{Ag}$ particles larger than $5.8 \mathrm{~nm}$. Comparable studies with $\mathrm{AgNO}_{3(\mathrm{aq})}$ impregnations on $\mathrm{SiO}_{2}{ }^{52}$ led to increased $\mathrm{Ag}$ PS and broad size distributions, which emphasizes the advantage of the developed synthesis technique. As a direct result of the higher calcination temperature (from 400 to $600{ }^{\circ} \mathrm{C}$ ), the amount of 
Ag clusters $(<1 \mathrm{~nm})$ is reduced from $6.4 \%$ to $1.7 \%$. The impact of the calcination temperature on the $\mathrm{Ag}$ PS of $>1 \mathrm{~nm}$ is insignificant, which underlines the high temperature stability of the synthesized Ag particles.

For all samples PXRD analysis was performed (Figure 3). PXRD provides integral information about the phase

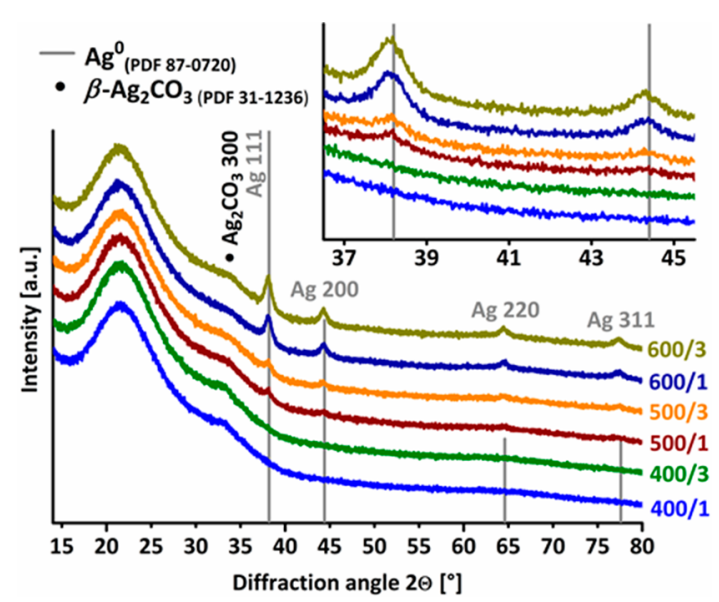

Figure 3. PXRD of $\mathrm{Ag} 5 / \mathrm{SiO}_{2}$ calcined at 400,500 , and $600{ }^{\circ} \mathrm{C}$ with 1 and $3 \mathrm{~h}$ dwell time. Inset represents a zoom of the $\mathrm{Ag} 111$ and $\mathrm{Ag} 200$ reflections.

compositions, and no remaining $\mathrm{AgNO}_{3}$ or $\mathrm{Ag}_{2} \mathrm{O}$ as byphase was detected. The broad diffuse signal between $16^{\circ}$ and $40^{\circ} 2 \Theta$ is assigned to amorphous $\mathrm{SiO}_{2}$. For samples calcined at $400{ }^{\circ} \mathrm{C}$ the present $\mathrm{Ag}$ nanoparticles are $\mathrm{X}$-ray amorphous, which is a result of the small Ag domains. With increasing calcination temperatures the $\mathrm{Ag}$ reflections start to appear and get well visible for applied $600{ }^{\circ} \mathrm{C}$. For the samples $\mathrm{Ag} 5 / \mathrm{SiO}_{2}$ $600 / 1$ and $600 / 3$ also the volume-weighed mean domain sizes and lattice parameter can be extracted from full pattern analysis, with $6.1 \pm 0.9 \mathrm{~nm}$ and $4.089 \pm 0.012 \AA$ for $600 / 1$ and $6.3 \pm 0.9 \mathrm{~nm}$ and $4.090 \pm 0.009 \AA$ for $600 / 3$. Thereby, the domain sizes are in good agreement with the results from STEM analysis showing only particles of $<5.8 \mathrm{~nm}$ for $\mathrm{Ag} 5 /$ $\mathrm{SiO}_{2} 600 / 1$. Within the uncertainty of the fitted results, all lattice parameters are in agreement with the reported reference of $4.086 \AA^{53}$ for $\mathrm{Ag}^{0}$. Besides, a diffuse signal at $37-39^{\circ} 2 \Theta$ assigned to $\mathrm{Ag}_{2} \mathrm{CO}_{3}$ is visible. With a decreasing calcination temperature, the $\mathrm{Ag}_{2} \mathrm{CO}_{3}$ moieties are increasing; further, as a function of time (4.5 month, absence of light) the $\mathrm{Ag}_{2} \mathrm{CO}_{3}$ is continuously growing and crystallizing (Figure S3).

For this study a $\alpha-\mathrm{Al}_{2} \mathrm{O}_{3}$ supported $\mathrm{Ag}$ reference sample was synthesized and labeled $\mathrm{Ag} 15 / \alpha-\mathrm{Al}_{2} \mathrm{O}_{3}$. In contrast to the applied $\mathrm{SiO}_{2}$ support, $\mathrm{AgNO}_{3}$ based impregnation on $\alpha-\mathrm{Al}_{2} \mathrm{O}_{3}$ (experimental details are described in the Supporting Information) led to the opposite effect resulting in large particles with a broad size distribution, ranging from nanoparticles of only a few nanometers up to particles of several micrometers (Figure S4 and Figure S5). Therefore, according to current patent literature, ${ }^{36}$ a Ag-oxalate source was used for the synthesis of a reference sample. This approach led to well dispersed Ag nanoparticles of $100-300 \mathrm{~nm}$ with a few particles being in the range of $20-40 \mathrm{~nm}$ (STEM analysis, Figure S6) but without particles of $<20 \mathrm{~nm}$. Therefore, the Agoxalate based $\mathrm{Ag} 15 / \alpha-\mathrm{Al}_{2} \mathrm{O}_{3}$ sample can be applied as a reference for larger $\mathrm{Ag}$ particles ${ }^{36}$ and, based on the $\mathrm{Ag}$ PS, can be circumscribed from $\mathrm{Ag} 5 / \mathrm{SiO}_{2}$ samples with $\mathrm{Ag}$ particles of
$<6 \mathrm{~nm}$. The quantitative XRD analysis using the Rietveld method determined the Ag loading for $\mathrm{Ag} 15 / \alpha-\mathrm{Al}_{2} \mathrm{O}_{3}$ to 14.0 wt $\%$, being in good agreement with nominal loading of 15.5 wt $\%$ and the results from ICP-OES of 12.4 wt \%.

Further, the crystalline domain size of $\mathrm{Ag} 15 / \alpha-\mathrm{Al}_{2} \mathrm{O}_{3}$ was calculated to $39.4 \mathrm{~nm}$ (Figure S7) with a calculated lattice parameter of $4.08603 \pm 0.00009 \AA$, being in very good agreement with the reference value. ${ }^{53}$ It seems reasonable that the present Ag particles of 100-300 nm detected by STEM analysis of $\mathrm{Ag} 15 / \alpha-\mathrm{Al}_{2} \mathrm{O}_{3}$ therefore consist of multiple $\mathrm{Ag}$ domains, very likely formed by sintering of smaller $\mathrm{Ag}$ particles of around $40 \mathrm{~nm}$ as calculated from PXRD, probably during the calcination procedure. Furthermore, PXRD analysis revealed no or an insignificant (XRD amorphous) amount of $\mathrm{Ag}_{2} \mathrm{CO}_{3}$ even after 6 months. This might be interpreted as strong tendency of $\mathrm{Ag}$ nanoparticles to activate and stabilize oxygen since formally, the $\mathrm{Ag}_{2} \mathrm{CO}_{3}$ formation is based on the reaction of $\mathrm{Ag}_{2} \mathrm{O}$ (here, rather $\mathrm{Ag}^{\delta+} \mathrm{O}_{x}$ ) with $\mathrm{CO}_{2}$. The stabilized oxygen species on $\mathrm{Ag}$ nanoparticles of $<6 \mathrm{~nm}$, in contrast to big or bulk-like Ag particles ( $>20 \mathrm{~nm}$, smallest size detected via STEM analysis), might be of rather oxidic character (without forming any $\mathrm{Ag}_{2} \mathrm{O}$ phase). This gives a first indication about the nature and reactivity of $\mathrm{Ag}$ nanoparticles and a pronounced size effect.

Catalytic Testing. Prior to testing the catalytic performance in the oxidation of $\mathrm{CO}$ to $\mathrm{CO}_{2}$, it is indispensable to properly activate the catalysts. As observed by PXRD, Ag nanoparticles show a strong tendency to form $\mathrm{Ag}_{2} \mathrm{CO}_{3}$. During the activation phase, the surface of the active material is cleaned by the decomposition of unwanted species like carbonates and oxides, potentially blocking reaction sites. Due to the decomposition temperature of $\mathrm{Ag}_{2} \mathrm{CO}_{3}$ of $175-225$ ${ }^{\circ} \mathrm{C}{ }^{54}$ and $\mathrm{Ag}_{2} \mathrm{O}$ of around $200{ }^{\circ} \mathrm{C},{ }^{44}$ the lowest meaningful pretreatment temperature is $200{ }^{\circ} \mathrm{C}$. All pretreatments were performed with $21 \% \mathrm{O}_{2}$ in $\mathrm{He}$. For the following $\mathrm{CO}$ oxidation test a three-cycle run is applied, whereby the first cycle is used as additional pretreatment step for cleaning the $\mathrm{Ag}$ particle surface and to reduce remaining $\mathrm{AgNO}_{3}$. The second and third cycles represent the actual $\mathrm{CO}$ oxidation performance test. In addition, the third cycle provides also information about the stability of the catalysts. We exclude poisoning effects by the product $\mathrm{CO}_{2}$ since under reaction conditions $\mathrm{Ag}_{2} \mathrm{CO}_{3}$ formation is not favored. Besides, a dependence of the reaction rates from the $\rho\left(\mathrm{CO}\right.$ and $\left.\mathrm{O}_{2}\right)$ indicates that the product desorption/poisoning has no impact on the rates (Figure S11).

To investigate the influence of the pretreatment conditions on the catalytic performance, the catalysts were activated at $200{ }^{\circ} \mathrm{C}$ for $12 \mathrm{~h}(200 / 12), 230{ }^{\circ} \mathrm{C}$ for $3 \mathrm{~h}(230 / 3), 300{ }^{\circ} \mathrm{C}$ for $3 \mathrm{~h}(300 / 3)$, or $300{ }^{\circ} \mathrm{C}$ for $12 \mathrm{~h}(300 / 12)$. For a direct comparison of the catalytic activity the temperatures reaching $10 \% \mathrm{CO}$ conversions are identified $\left(T_{10 \%}\right)$. With a stepwise increase of the temperature and dwell time, all catalysts tested were significantly increasing in their catalytic performance. Figure 4 shows the impact on the $T_{10 \%}$ of the $\mathrm{Ag} 5 / \mathrm{SiO}_{2} 400 / 1$ and $600 / 1$ catalysts for three different pretreatment conditions (all $T_{10 \%}$ values are listed in Table 2 ). The $400 / 1$ sample shows a huge dependency of the $T_{10 \%}$ values upon different pretreatments. In particular, the first catalytic cycle deviates from the second and third cycles. This effect is more significant for the milder pretreatment conditions $\left(230 / 3 \Delta T_{\mathrm{cl}-\mathrm{c} 3}=91\right.$ ${ }^{\circ} \mathrm{C}, 300 / 3 \Delta T_{\mathrm{cl}-\mathrm{c} 3}=27^{\circ} \mathrm{C}$ ), which is most likely explained by the transformation of the residual $\mathrm{AgNO}_{3}(\sim 6 \%)$ to catalytically active $\mathrm{Ag}^{0}$. The activity of the second and third cycles of 


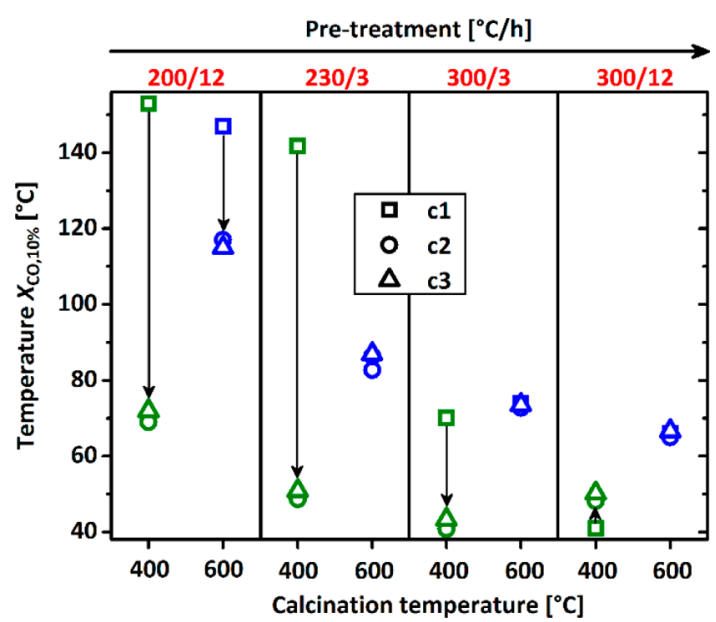

Figure 4. Temperatures for $10 \% \mathrm{CO}$ conversion for cycles $1-3$ (c1c3) for $\mathrm{Ag} 5 / \mathrm{SiO}_{2}$ catalysts calcined at 400 and $600{ }^{\circ} \mathrm{C}$ with $1 \mathrm{~h}$ dwell for pretreatment conditions 200/12, 230/3, 300/3, and 300/12 (see also Table 2).

Table 2. Overview of Temperature Needed for $10 \% \mathrm{CO}$ Conversion $\left(T_{10 \%}\right)$ for Different Pretreatments for Cycles 1-3 for Catalysts $\mathrm{Ag5} / \mathrm{SiO}_{2}$ Calcined at 400 and $600{ }^{\circ} \mathrm{C}$ for $1 \mathrm{~h}$ and $\mathrm{Ag} 15 / \alpha-\mathrm{Al}_{2} \mathrm{O}_{3}$

\begin{tabular}{ccccc} 
& & \multicolumn{3}{c}{$T_{10 \%}\left[{ }^{\circ} \mathrm{C}\right]$} \\
\cline { 3 - 5 } pretreatment & cycle & $\mathrm{Ag} 5 / \mathrm{SiO}_{2} 400 / 1$ & $\mathrm{Ag} 5 / \mathrm{SiO}_{2} 600 / 1$ & $\mathrm{Ag} 15 / \alpha-\mathrm{Al}_{2} \mathrm{O}_{3}$ \\
$200 / 12$ & 1 & 153 & 147 & \\
& 2 & 69 & 117 & \\
$230 / 3$ & 3 & 72 & 115 & \\
& 1 & 142 & 83 & \\
$300 / 3$ & 2 & 48 & 86 & 132 \\
& 3 & 51 & 87 & 137 \\
$300 / 12$ & 1 & 70 & 74 & \\
& 2 & 41 & 73 & \\
& 3 & 43 & 74 & \\
& 2 & 41 & 66 & \\
\hline
\end{tabular}

sample $400 / 1$ is thereby much higher for all pretreatments (lower $T_{10 \%}$ values) except for $300 / 12$. Here, the pretreatment leads already to first deactivation and sintering events for the $400 / 1$ sample which can be seen in the increased $T_{10 \%}$ from cycle 1 to cycle 2 . Luo et al. ${ }^{55}$ have already shown that for unsupported $2 \mathrm{~nm}$ sized $\mathrm{Ag}$ nanoparticles the corresponding Tammann temperature is below $100{ }^{\circ} \mathrm{C}$, which makes sintering for the present silica supported nanoparticles in a comparable size range a likely deactivation mechanism. The 600/1 sample shows, upon cycling within a given pretreatment, stable $T_{10 \%}$ values $\left(\Delta T_{\mathrm{cl}-\mathrm{c} 3}=1-3{ }^{\circ} \mathrm{C}\right)$, supporting a complete calcination (no $\mathrm{AgNO}_{3}$, Figure $\mathrm{S} 1 \mathrm{~B}$ ). The higher activity with higher pretreatment temperatures can be ascribed to a more complete surface purification (e.g., from $\mathrm{Ag}_{2} \mathrm{CO}_{3}$ ) strongly emphasizing the importance of a dedicated pretreatment for $\mathrm{Ag}$ catalysts, especially for $\mathrm{Ag}$ nanoparticles. This interpretation is supported by the behavior of the aged and $\mathrm{Ag}_{2} \mathrm{CO}_{3}$-rich $\mathrm{Ag5} / \mathrm{SiO}_{2}$ samples (stored for 4.5 months, Figure S3), which show after a pretreatment at conditions of $300 / 12$ a reduced activation upon cycling (Figure S8). For the aged sample 400/ 1 the first cycle after $300 / 12$ pretreatment is additionally needed to purify the sample from $\mathrm{Ag}_{2} \mathrm{CO}_{3}$ leading to further activation of the catalyst.

Besides, an ongoing desorption of oxygen upon higher pretreatment temperatures has to be considered. This effect is explained by the adsorbed atomic oxygen, which is strongly bound and acts as inhibitor for the adsorption of $\mathrm{CO}$ in the close proximity. The desorption of adsorbed atomic oxygen offers more adsorption sites now also available for $\mathrm{CO} .{ }^{47}$ This would result in an increased rate for $\mathrm{CO}$ oxidation caused by harsher pretreatment conditions and is in agreement with the results for the $\mathrm{Ag} 5 / \mathrm{SiO}_{2}$ catalysts. However, since the fresh $400 / 1$ sample shows first sintering effects at conditions of 300/ 12 , for the following testings and quantifications the pretreatment conditions are fixed to conditions of $300 / 3$ as suitable upper limit, resulting in the highest activity without deactivation.

For comparison, reference $\mathrm{Ag} 15 / \alpha-\mathrm{Al}_{2} \mathrm{O}_{3}$ was additionally measured in $\mathrm{CO}$ oxidation after $300 / 3$ pretreatment (Table 2 and Figure S9). The catalyst shows a stable performance with $T_{10 \%}$ values of $137^{\circ} \mathrm{C}$ for cycles 2 and 3 . Although the sample contains the 3-fold amount of $\mathrm{Ag}$, it is almost half as active as sample $\mathrm{Ag5} / \mathrm{SiO}_{2} 600 / 1$, underlining the high activity of $\mathrm{Ag5} /$ $\mathrm{SiO}_{2}$ catalysts.

To gain further insights into the activation procedure of the $400 / 1$ sample during cycle 1 , respectively between cycles 1 and 2 , its $\mathrm{CO}$ oxidation performance, tested for three cycles (c1c3), is compared to the noncalcined $\mathrm{AgNO}_{3} / \mathrm{SiO}_{2}$ precursor. Figure $5 \mathrm{~A}$ shows the light-off curves of the precursor, dried at $110{ }^{\circ} \mathrm{C}$, and pretreatment at 300/3. A distinct discrepancy between the first and second cycle is observed, accompanied by a pronounced activation of the sample. The catalyst ignites as soon as $\mathrm{AgNO}_{3}$ starts to decompose (see also Figure S1A). After the pretreatment of $300 / 3$ obviously only a minor fraction of $\mathrm{AgNO}_{3}$ is converted/thermolyzed to $\mathrm{Ag}^{0}$ nanoparticles, explaining the low conversion for the beginning of the first cycle. The effect of an increased activity is, strongly weakened, still visible for the third cycle. The activation of the precursor within the cycles is also monitored by a shift of the $T_{10 \%}$ values (indicated in Figure 5 as dashed line). A direct comparison to the light-off curves of the $400 / 1$ sample in Figure 5B emphasizes a similar activation behavior of these samples. As a consequence, the activation of the 400/1 sample (with $6 \% \mathrm{AgNO}_{3}$ ) within the cycling is coupled to the pretreatment conditions and is explained by the transformation of the residual $\mathrm{AgNO}_{3}$ to $\mathrm{Ag}^{0}$ particles or clusters. Further, stable $T_{10 \%}$ values of the $400 / 1$ sample for the second and third cycle after milder $(230 / 3,300 / 3)$ pretreatment indicate a complete conversion of the $\mathrm{AgNO}_{3}$ within the first cycle (Figure 4). The harsh pretreatment of 300/12 resulted already in a $\mathrm{AgNO}_{3}$-free catalyst, indicated by the absence of any activation upon cycling. Since after calcination at conditions of 600/1 no residual $\mathrm{AgNO}_{3}$ is detected (Figure S1B), no activation between the first and third cycle is observed after 300/3 pretreatment (Figure 4 and Figure S10), which underlines the described correlation.

The in situ autocatalytic conversion of residual $\mathrm{AgNO}_{3}$ to $\mathrm{Ag}^{0}$ induced by the $\mathrm{CO}$ oxidation feed has a significant impact on the catalytic performance. In comparison to the thermolysis/calcination approach $\left(>500{ }^{\circ} \mathrm{C}\right)$ the in situ creation of $\mathrm{Ag}$ nanoparticles is a rather mild and elegant method to create and stabilize even smaller particles or clusters, showing $\mathrm{CO}$ oxidation activity already at $30{ }^{\circ} \mathrm{C}$ (Figure 5B). For the investigation of the emerging PS during 


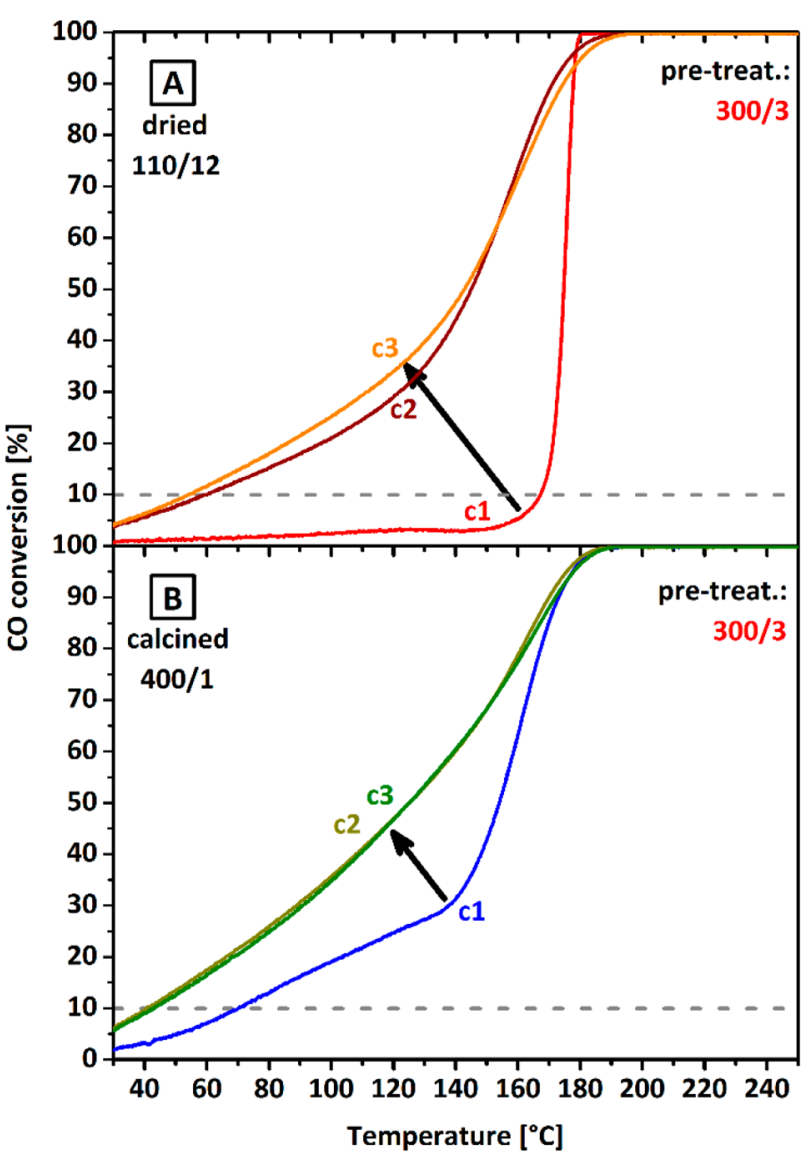

Figure 5. $\mathrm{CO}$ oxidation cycles $(\mathrm{cl}-\mathrm{c} 3)$ for $\mathrm{AgNO}_{3} / \mathrm{SiO}_{2}$ precursor dried at $110^{\circ} \mathrm{C}$ for $12 \mathrm{~h}(110 / 12)(\mathrm{A})$ and $\mathrm{Ag} 5 / \mathrm{SiO}_{2}$ catalyst calcined at $400{ }^{\circ} \mathrm{C}$ for $1 \mathrm{~h}(400 / 1)$ (B). Both samples were pretreated at 300 ${ }^{\circ} \mathrm{C}$ for $3 \mathrm{~h}(300 / 3)$.

the in situ reduction of $\mathrm{AgNO}_{3}$ during $\mathrm{CO}$ oxidation, the $\mathrm{Ag}$ PS distributions of freshly synthesized $\mathrm{Ag} 5 / \mathrm{SiO}_{2}$ samples $400 /$ 1 and $600 / 1$ were compared to their spent counterparts after $\mathrm{CO}$ oxidation (Figure 6). The fraction of particles of $>6 \mathrm{~nm}$ was determined to $<1 \%$ for the samples before and after catalysis, thereby supporting their high sintering stability. The PS distributions of the 400/1 sample before and after three cycles of $\mathrm{CO}$ oxidation are presented in Figure 6A. The fresh sample exhibits a median PS of $2.0 \mathrm{~nm}$ with a fraction of $6.4 \%$ on $\mathrm{Ag}$ clusters of $<1 \mathrm{~nm}$ (approximately $<50 \mathrm{Ag}$ atoms per particle). During the CO oxidation cycles the median PS is further decreased to $1.7 \mathrm{~nm}$, also indicated by the increased moieties of $\mathrm{Ag}$ clusters to $14.2 \%$. The higher fraction of $\mathrm{Ag}$ clusters is attributed to its in situ formation upon $\mathrm{CO}$ oxidation and conversion of residual $\mathrm{AgNO}_{3}$. Figure 6B shows the PS distribution of the $600 / 1$ catalyst. The fresh sample has a median PS of $2.3 \mathrm{~nm}$, thereby being slightly larger compared to the fresh 400/1 sample. Also the fraction of Ag clusters of $<1$ $\mathrm{nm}$, determined to $1.7 \%$, is smaller. After CO oxidation the median of the present PS $(2.4 \mathrm{~nm})$ and the fraction of $\mathrm{Ag}$ clusters $(1.6 \%)$ are almost unchanged compared to the fresh sample, which is in very good agreement with the stable catalytic activity and $T_{10 \%}$ values (see insets of Figure 6). The $400 / 1$ catalyst shows, in contrast, a significant increase in CO oxidation activity upon cycling $\left(T_{10 \%}\right.$ decreased by $\left.27{ }^{\circ} \mathrm{C}\right)$. This is in direct correlation to the in situ formation of $\mathrm{Ag}$ clusters, strongly indicating its huge impact on catalysis.

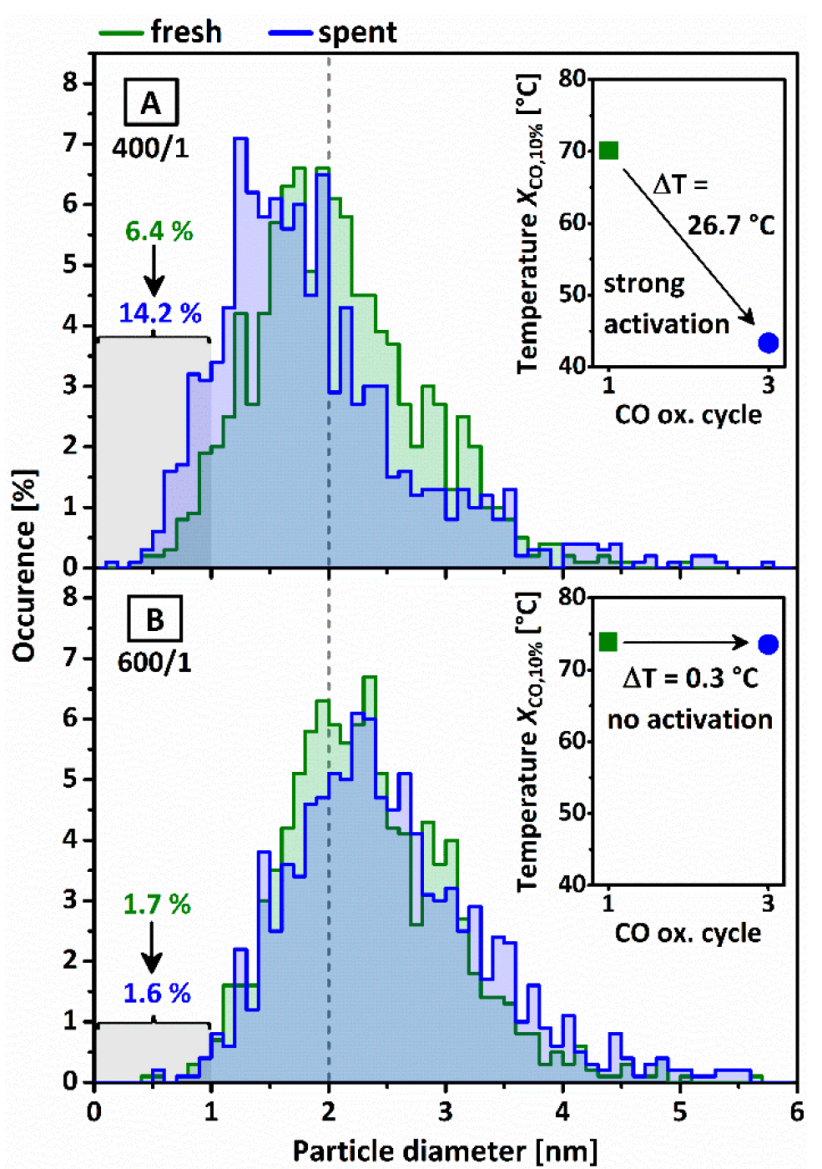

Figure 6. PS distributions from STEM (0.1 nm bin size) for Ag5/ $\mathrm{SiO}_{2}$ catalysts calcined at 400/1 (A) and 600/1 (B). Shown are fresh (green) and spent samples (blue) after three cycles of $\mathrm{CO}$ oxidation after $300 / 3$ pretreatment, as well as cumulative percentages for the fractions of $<1.0 \mathrm{~nm}$ for fresh to spent samples. Insets show $T_{10 \%}$ for first (green) and third cycle (blue).

These findings are not consistent with the results of Lim et al. ${ }^{18}$ claiming that $\mathrm{Ag}$ particles of $<3 \mathrm{~nm}$ are no good catalysts for $\mathrm{CO}$ oxidation and of $\mathrm{Qu}$ et al. ${ }^{17}$ reporting that catalysts with Ag PS of 6-8 $\mathrm{nm}$ are the most active for $\mathrm{CO}$ oxidation. Those results are indicating a structure sensitivity with inferior catalytic activity for nanoparticles of $<3 \mathrm{~nm}$ and are in contrast to our work. This discrepancy is likely explained by an inappropriate pretreatment and the low reaction temperatures applied in their studies.

To exclude different reaction mechanisms for samples Ag5/ $\mathrm{SiO}_{2}$, the reaction order at $100{ }^{\circ} \mathrm{C}$ for selected catalysts was calculated after $300 / 3$ pretreatment and performing one $\mathrm{CO}$ oxidation cycle to $250{ }^{\circ} \mathrm{C}$ for a final $\mathrm{AgNO}_{3}$ removal and $\mathrm{Ag}$ cluster formation (Figures S11 and S12). In general, for all samples the reaction order is below 1 and higher for $\mathrm{CO}$ than for $\mathrm{O}_{2}$, which indicates a higher dependence on the $\rho(\mathrm{CO})$ than on $\rho\left(\mathrm{O}_{2}\right)$. Values for catalysts $500 / 1,600 / 1$, and $600 / 3$ range between $n\left(\mathrm{O}_{2}\right)=0.30-0.32$ and $n(\mathrm{CO})=0.63-0.68$. This indicates a higher coverage with oxygen in comparison to $\mathrm{CO}$ as general feature. For sample $\mathrm{Ag} 5 / \mathrm{SiO}_{2} 400 / 1$ the reaction orders are lower with $n\left(\mathrm{O}_{2}\right)=0.09$ and $n(\mathrm{CO})=0.41$. This implies that the reaction rates are almost independent of the $\rho\left(\mathrm{O}_{2}\right)$ and that the activation of $\mathrm{O}_{2}$ is facile. Since Ag tends to form also subsurface oxygen species, the particle and/or cluster size might serve as descriptor for this behavior and vice 
versa; small clusters stabilize oxygen rather near the surface. This discrepancy between sample $400 / 1$ and the samples calcined at higher temperatures is interpreted as a result of the highly active Ag clusters. They are in situ created during the first CO oxidation cycle for the 400/1 sample, and their distinctness is also visible in the different kinetic parameters (reaction orders).

Evaluation of the Silver-Oxygen Interaction. To investigate the ability of $\mathrm{Ag}$ catalyst systems to activate $\mathrm{O}_{2}$, microcalorimetry experiments were conducted (Figure 7). The

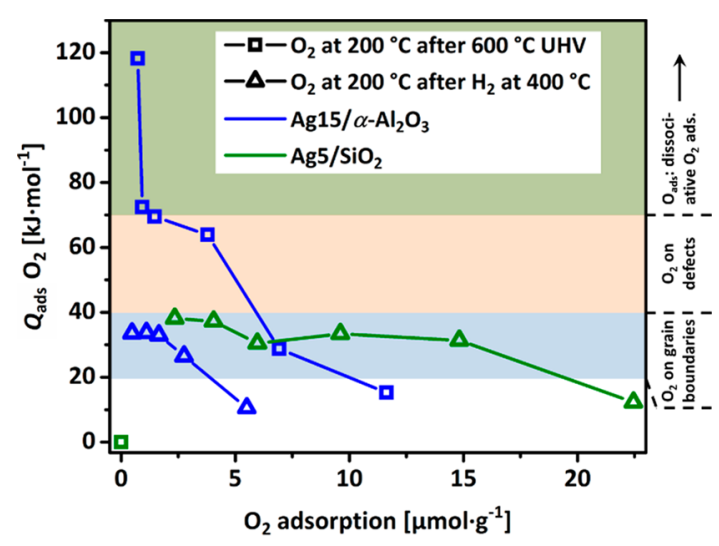

Figure 7. Microcalorimetric oxygen adsorption on $\mathrm{Ag} 15 / \alpha-\mathrm{Al}_{2} \mathrm{O}_{3}$ and $\mathrm{Ag} 5 / \mathrm{SiO}_{2}$ calcined at $600 / 1 . \mathrm{O}_{2}$ adsorption was performed at $200{ }^{\circ} \mathrm{C}$ after pretreatment at $600{ }^{\circ} \mathrm{C}$ in UHV and after $400{ }^{\circ} \mathrm{C}$ with $\mathrm{H}_{2}$. On the right the corresponding adsorption sites are shown based on DFT calculations.

$\mathrm{Ag} 15 / \alpha-\mathrm{Al}_{2} \mathrm{O}_{3}$ sample and the $\mathrm{AgNO}_{3} / \mathrm{SiO}_{2}$ precursor were both in situ calcined at $600{ }^{\circ} \mathrm{C}$ for $1 \mathrm{~h}$ prior to the $\mathrm{O}_{2}$ dosing at $200{ }^{\circ} \mathrm{C}$. The integral heat of adsorption $\left(Q_{\mathrm{ads}}\right)$ of the $\mathrm{Ag} 15 / \alpha$ $\mathrm{Al}_{2} \mathrm{O}_{3}$ sample is in the range of $120 \mathrm{~kJ} \cdot \mathrm{mol}^{-1}$ and decreases upon titrating to a plateau at $\sim 70 \mathrm{~kJ} \cdot \mathrm{mol}^{-1}$ and finally reaches values below $30 \mathrm{~kJ} \cdot \mathrm{mol}^{-1}$. On the basis of DFT calculation for the adsorption energy $\left(E_{\mathrm{ads}}\right)$ of oxygen on various $\mathrm{Ag}$ surfaces (for details see Supporting Information), the experimental results are interpreted as dissociatively activated oxygen species, with heats of adsorption in the range of $120-70 \mathrm{~kJ}$. $\mathrm{mol}^{-1}$, followed by molecular oxygen adsorbed on defects and grain boundaries $\left(Q_{\mathrm{ads}}\right.$ in the range of $\left.60-20 \mathrm{~kJ} \cdot \mathrm{mol}^{-1}\right)$. The $\mathrm{SiO}_{2}$ supported $\mathrm{Ag}$ nanoparticles show no interaction with the dosed $\mathrm{O}_{2}$ at $200{ }^{\circ} \mathrm{C}$. This is explained by the already stable oxygen saturated state forming $\mathrm{Ag}^{\delta+} \mathrm{O}_{x}$ species during in situ calcination (mainly from $\mathrm{AgNO}_{3}$ ) that are consequently unable to further activate molecular oxygen. Subsequently, to remove oxygen species in and on $\mathrm{Ag}$, both samples were pretreated in hydrogen at $400{ }^{\circ} \mathrm{C}$. Temperature-programmed reduction (TPR) experiments under $0.25 \% \mathrm{H}_{2}$ atmosphere were already performed to monitor the consumption of different kind of oxygen species by $\mathrm{H}_{2}$ under the formation of water (Figure S13), showing that $400{ }^{\circ} \mathrm{C}$ is a reasonable temperature for a complete reduction of $\mathrm{Ag} . \mathrm{H}_{2} \mathrm{O}$ events at higher temperatures are related to support effects. Titrating the reduced samples again with $\mathrm{O}_{2}$ led qualitatively to comparable results for both samples, with $Q_{\text {ads }}$ values in the range of $30-40 \mathrm{~kJ} \cdot \mathrm{mol}^{-1}$. The $\mathrm{Ag}$ nanoparticles offer more adsorption sites for oxygen, which are according to DFT calculations for both samples in the regime of molecular oxygen on different surfaces. These results show that the oxygen species were successfully removed by the reducing treatment (also the stabilized oxygen on $\mathrm{Ag}$ nanoparticles). Besides, it is clearly shown that for a dissociative activation of oxygen, oxygen species in and on $\mathrm{Ag}$ (not too ionic and stable) have to be already present. If not, oxygen is only molecularly adsorbed, since the oxygen-free $\mathrm{Ag}^{0}$ particles have a closed $d$-band and are inactive. ${ }^{56}$ After the microcalorimetry experiments a median PS of $2.5 \mathrm{~nm}(99.9 \%<$ $7.2 \mathrm{~nm}$, Figure S14) is found via STEM analysis, confirming that the in situ created sample is comparable to $\mathrm{Ag} 5 / \mathrm{SiO}_{2} 600 /$ 1 and representative for the series of $\mathrm{Ag}$ nanoparticles stabilized on $\mathrm{SiO}_{2}$. However, the results obtained by the integral microcalorimetry offer valuable insights in the nature of the $\mathrm{Ag}-\mathrm{O}$ interaction, but a surface quantification of $\mathrm{Ag}$ (or an identification of the number of reaction sites on $\mathrm{Ag}$ ) due to the subsurface contributions is very difficult.

To further evaluate the strength of the $\mathrm{Ag}-\mathrm{O}$ interaction on the surface, we have to introduce a probe molecule, which interacts with the partially oxidized $\mathrm{Ag}^{\delta+} \mathrm{O}_{x}$ and is unable to develop a Ag subsurface chemistry. For this purpose, ethylene $\left(\mathrm{C}_{2} \mathrm{H}_{4}\right)$ is identified since the $\mathrm{Ag}^{\delta+} \mathrm{O}_{x}$ surface behaves like a selective "chromatographic column" and $\mathrm{C}_{2} \mathrm{H}_{4}$ adsorbs easily. Besides, it is well-known that metallic Ag is not able to interact with $\mathrm{C}_{2} \mathrm{H}_{4}$ since its electronic configuration of $\mathrm{s}^{1} \mathrm{~d}^{10}$ does not allow transferring electrons to the Ag d-band. ${ }^{22,57,58}$ This fact was confirmed for a $\mathrm{Ag} 5 / \mathrm{SiO}_{2} 600 / 1$ sample reduced at 400 ${ }^{\circ} \mathrm{C}$ in $5 \% \mathrm{H}_{2}$, resulting in a metallic supported Ag catalyst. This sample showed no heat evolution upon $\mathrm{C}_{2} \mathrm{H}_{4}$ dosing via microcalorimetry and therefore no interaction with $\mathrm{C}_{2} \mathrm{H}_{4}$. For the partially oxidized $\mathrm{Ag}^{\delta+}$, electron density from the $\mathrm{Ag}^{0} \mathrm{~d}$ band is removed which enables the donation of $\pi$-electrons. This interaction allows $\mathrm{C}_{2} \mathrm{H}_{4}$ to be a suitable sensor for the titration of all kinds of $\mathrm{Ag}^{+}$sites from $\mathrm{Ag}_{2} \mathrm{O}, \mathrm{AgNO}_{3}$, and $\mathrm{Ag}^{\delta+}$ sites from partially oxidized $\mathrm{Ag}^{\delta+} \mathrm{O}_{x}$. Furthermore, the $\mathrm{C}_{2} \mathrm{H}_{4}$ interaction strength with $\mathrm{Ag}^{\delta+} \mathrm{O}_{x}$ is also an indirect measurement for the strength of $\mathrm{Ag}-\mathrm{O}$ interaction, since the binding strength of $\mathrm{C}_{2} \mathrm{H}_{4}$ depends on the strength of interaction of oxygen with $\mathrm{Ag}$ and the corresponding acceptance of $\pi$ electrons. However, for a correct comparison of the adsorption on $\mathrm{Ag}$ some important criteria have to be fulfilled: (I) the $\mathrm{Ag}$ surface sites have to be available for $\mathrm{C}_{2} \mathrm{H}_{4}$ to adsorb. This implies a proper pretreatment sequence. (II) Any interaction of the support materials and $\mathrm{C}_{2} \mathrm{H}_{4}$ has to be ruled out. Therefore, a pure $\mathrm{SiO}_{2}$ sample that was equally treated compared with the $\mathrm{Ag} 5 / \mathrm{SiO}_{2}$ samples (blind impregnation with $\mathrm{H}_{2} \mathrm{O}$ ) was measured. Due to the absence of any heat evolution upon $\mathrm{C}_{2} \mathrm{H}_{4}$ dosing, the support is seen as inert.

Figure 8 illustrates the results of the microcalorimetric $\mathrm{C}_{2} \mathrm{H}_{4}$ adsorption experiments and the corresponding integral heat evolutions. At first, the $\mathrm{AgNO}_{3} / \mathrm{SiO}_{2}$ precursor was in situ activated at $300 / 3$, and subsequently $\mathrm{C}_{2} \mathrm{H}_{4}$ was adsorbed. The $Q_{\mathrm{ads}}$ is in the range of $85-90 \mathrm{~kJ} \cdot \mathrm{mol}^{-1}$ and decreases gradually upon dosing. The adsorption of the $\mathrm{C}_{2} \mathrm{H}_{4}$ molecules was reversible (qualitatively and quantitatively under vacuum treatment, $\left.90 \mu \mathrm{mol} \cdot \mathrm{g}^{-1}\right)$ and for this sample very likely related to $\mathrm{Ag}^{\delta+} \mathrm{O}_{x}$ from $\mathrm{Ag}$ nanoparticles and $\mathrm{Ag}^{+}$adsorption centers from residual $\mathrm{AgNO}_{3}$. For a possible discrimination between the nature of the $\mathrm{Ag}-\mathrm{O}$ interaction of $\mathrm{Ag}$ clusters $(<1 \mathrm{~nm})$ and $\mathrm{Ag}$ nanoparticles $(1-6 \mathrm{~nm})$ the precursor $\mathrm{AgNO}_{3} / \mathrm{SiO}_{2}$ was additionally in situ reduced using $\mathrm{CO}$ as reduction agent, comparable to one $\mathrm{CO}$ oxidation cycle as demonstrated in Figure 5. As shown before, the reductive $\mathrm{CO}$ atmosphere in situ reduces the $\mathrm{Ag}^{+}$species of the residual $\mathrm{AgNO}_{3}$ under the formation of $\mathrm{Ag}$ nanoparticles and clusters. The resulting $\mathrm{C}_{2} \mathrm{H}_{4}$ adsorption led to $Q_{\mathrm{ads}}$ in the range of $100 \mathrm{~kJ} \cdot \mathrm{mol}^{-1}$, which is a 
A

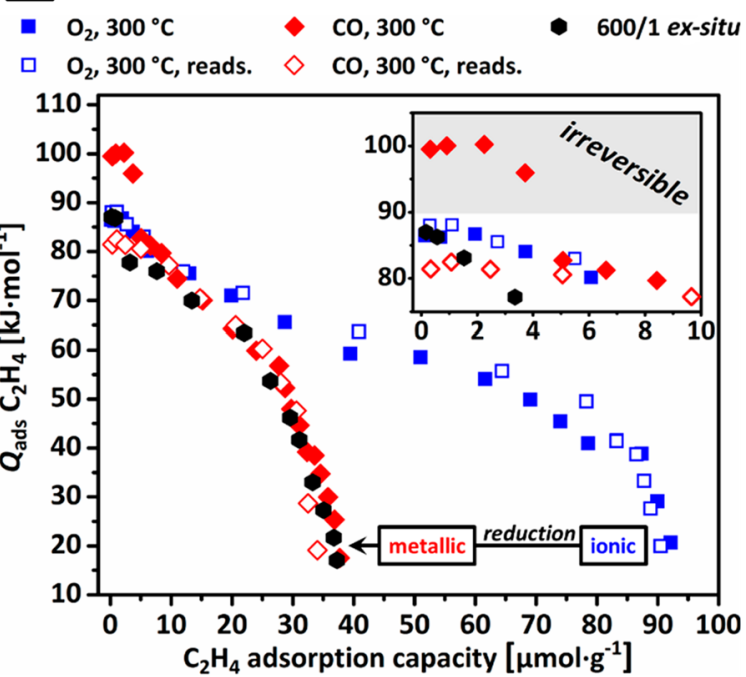

B

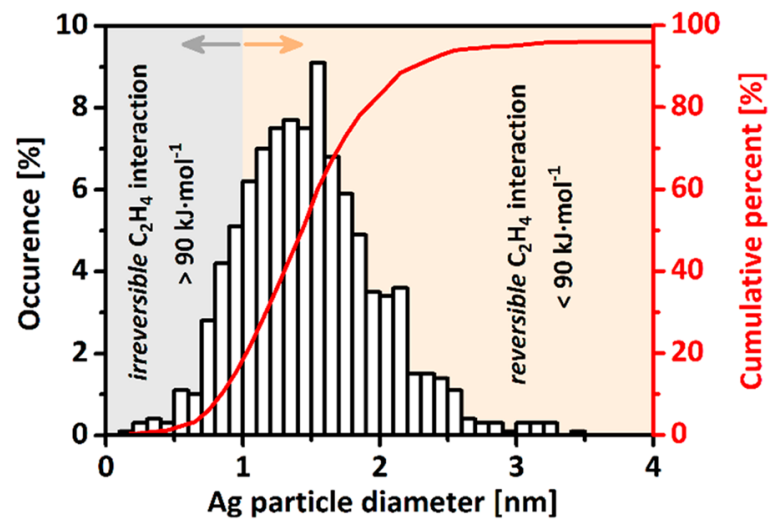

Figure 8. Microcalorimetric integral heat of adsorbed $\mathrm{C}_{2} \mathrm{H}_{4}\left(Q_{\mathrm{ads}}\right.$ $\left.\mathrm{C}_{2} \mathrm{H}_{4}\right)$ at $40{ }^{\circ} \mathrm{C}$ on $\mathrm{AgNO}_{3} / \mathrm{SiO}_{2}$ together with the corresponding $\mathrm{C}_{2} \mathrm{H}_{4}$ adsorption capacity after in situ pretreatment at conditions of $300 / 3$ in synthetic air (blue squares), subsequent $\mathrm{CO}$ oxidation feed exposure at $300{ }^{\circ} \mathrm{C}$ (red diamonds) together with the respective readsorptions (empty symbols). As comparison, sample $\mathrm{Ag} 5 / \mathrm{SiO}_{2}$ ex situ calcined at conditions of 600/1 with subsequent in situ 300/3 pretreatment is shown as black hexagons (A). PS distribution from STEM with $0.1 \mathrm{~nm}$ bin size for spent sample $\mathrm{AgNO}_{3} / \mathrm{SiO}_{2}$ after in situ $300 / 3$ synthetic air treatment, $\mathrm{CO}$ reduction at $300{ }^{\circ} \mathrm{C}$, and $\mathrm{C}_{2} \mathrm{H}_{4}$ microcalorimetry (B).

difference in the maximum $Q_{\mathrm{ads}}$ of $13 \mathrm{~kJ} \cdot \mathrm{mol}^{-1}$ (compared to the adsorption without the reduction in $\mathrm{CO}$ atmosphere). Further, the amount of adsorption centers was reduced from $90 \mu \mathrm{mol} \cdot \mathrm{g}^{-1}$ to $38 \mu \mathrm{mol} \cdot \mathrm{g}^{-1}$, which matches very well with loss of $\mathrm{Ag}^{+}$sites on the expense of $\mathrm{Ag}^{\delta+} \mathrm{O}_{x}$ sites. For the readsorption (after $\mathrm{HV}$ treatment) on the reduced sample the highest detected $Q_{\mathrm{ads}}$ is in the range of $80-85 \mathrm{~kJ} \cdot \mathrm{mol}^{-1}$ which indicates the irreversibility of the $\mathrm{Ag}^{\delta+} \mathrm{O}_{x}-\mathrm{C}_{2} \mathrm{H}_{4}$ interaction due to integral heat evolutions of $>90 \mathrm{~kJ} \cdot \mathrm{mol}^{-1}$. The ex situ calcined 600/1 sample without Ag clusters showed upon $\mathrm{C}_{2} \mathrm{H}_{4}$ titration also $Q_{\mathrm{ads}}$ in the range of $85-90 \mathrm{~kJ} \cdot \mathrm{mol}^{-1}$. This implies that the in situ created $\mathrm{Ag}$ clusters exhibit $\mathrm{Ag}^{\delta+} \mathrm{O}_{x}$ species which are more ionic/oxidic than the $\mathrm{Ag}$ nanoparticles. The amount of irreversible sites was in the range of $10 \%(3.7$ $\mu \mathrm{mol} \cdot \mathrm{g}^{-1}$ of $\left.38 \mu \mathrm{mol} \cdot \mathrm{g}^{-1}\right)$ and in reasonable agreement with the amount of Ag clusters of the 400/1 samples after CO oxidation. Again, the sample with the irreversible adsorption sites from the microcalorimetry study was investigated via STEM for a PS analysis. Figure $8 \mathrm{~B}$ shows the corresponding histogram of the PS distribution being in very good agreement with the PS distribution of the 400/1 sample (see also Figure 6). This strongly indicates a direct correlation between the number of $\mathrm{Ag}$ clusters and the number of irreversible adsorption sites. These adsorption sites, binding the oxygen species stronger (more oxidic), might also be responsible for the lowered reaction orders and the higher ability in activating oxygen within a catalytic cycle. Finally, an inverse trend for the strength of the Ag-O interaction and the corresponding PS and ionicity is manifested by complementary techniques (PXRD, STEM, and microcalorimetry): bulk-like (20-300 $\mathrm{nm})<\mathrm{Ag}$ nanoparticles $(1-6 \mathrm{~nm})<\mathrm{Ag}$ clusters $(<1 \mathrm{~nm})$.

Correlation of Ag Surface Area and Catalytic Activity. For a better comparison and investigation of catalytic relations it is necessary to determine the specific surface area of a catalyst. Conventional analysis of Ag surface areas is done by oxygen involving methods ${ }^{59-61}$ which are from our point of view very challenging. Due to the complex $\mathrm{Ag}-\mathrm{O}$ chemistry, oxygen might be located on the surface or in the subsurface/ bulk of Ag, since the low oxophilicity enables diffusion processes. So any techniques involving oxygen species (direct titration or consumption of prestored) is ruled out. Determining the geometric Ag surface by TEM analysis would also give a meaningless number, not correlating with the relevant sites. Therefore, we used the already introduced concept of partially oxidized Ag samples to interact with $\mathrm{C}_{2} \mathrm{H}_{4}$ as probe molecule of choice as for the microcalorimetric study. In comparison to the microcalorimetric setup (static and semiquantitative), we combined this idea with a temporal analysis of products approach at atmospheric pressure (atmTAP ${ }^{50}$ ). The $\mathrm{C}_{2} \mathrm{H}_{4}$ is dosed at $40{ }^{\circ} \mathrm{C}$ into a high-speed transient fixed bed operating under plug flow conditions as described in the Experimental Section. By use of this setup, the calculated $\mathrm{C}_{2} \mathrm{H}_{4}$ adsorption capacities are determined under conditions comparable to standard catalytic test reactors creating highly reliably correlations.

Figure S16 illustrates the principle of measurement. By comparison of the reactor residence time of $\mathrm{C}_{2} \mathrm{H}_{4}$ with the nonadsorbing reference $\mathrm{Ar}$, the amount of adsorbed $\mathrm{C}_{2} \mathrm{H}_{4}$ can be calculated from the mass balance. Let the signal for $\mathrm{C}_{2} \mathrm{H}_{4}$ as a function of time $t$ be denoted by $S(t)$ and the total volumetric flow rate by $F_{\mathrm{V}}$. From the mass balance it follows that the number of moles of adsorbed molecules $N_{\text {ad }}$ per gram catalyst is given by

$$
\frac{N_{\mathrm{ad}}}{m_{\mathrm{cat}}}=\frac{c_{\mathrm{C} 2 \mathrm{H} 4}}{F_{\mathrm{V}} m_{\mathrm{cat}}} \int_{0}^{\infty} 1-\frac{S(t)}{S(\infty)} \mathrm{d} t
$$

where $c_{\mathrm{C} 2 \mathrm{H} 4}$ is the molar concentration of $\mathrm{C}_{2} \mathrm{H}_{4}$ and $S(\infty)$ is the steady-state signal reached after the mean breakthrough time. Since $c_{\mathrm{C} 2 \mathrm{H} 4}$ is very low, indeed $<0.5 \%$, we can neglect the change of $F_{\mathrm{V}}$ due to adsorption and consider it a constant. The resulting amounts of adsorbed $\mathrm{C}_{2} \mathrm{H}_{4}$ are presented in Figure 9A showing the average over three measurements for each sample. All measurements were performed on $\mathrm{Ag} 5 / \mathrm{SiO}_{2}$ samples pretreated at $300 / 3$. Samples without remaining $\mathrm{AgNO}_{3}$ like 500/1, 500/3, 600/1, and 600/3 are all in the same range with an average $\mathrm{C}_{2} \mathrm{H}_{4}$ adsorption capacity of 28.3 $\mu \mathrm{mol} \cdot \mathrm{g}_{\mathrm{cat}}{ }^{-1}, 25.9 \mu \mathrm{mol} \cdot \mathrm{g}_{\mathrm{cat}}{ }^{-1}, 30.8 \mu \mathrm{mol} \cdot \mathrm{g}_{\mathrm{cat}}{ }^{-1}$, and $31.5 \mu \mathrm{mol}$. $\mathrm{g}_{\mathrm{cat}}{ }^{-1}$, respectively. These results indicate that samples calcined 

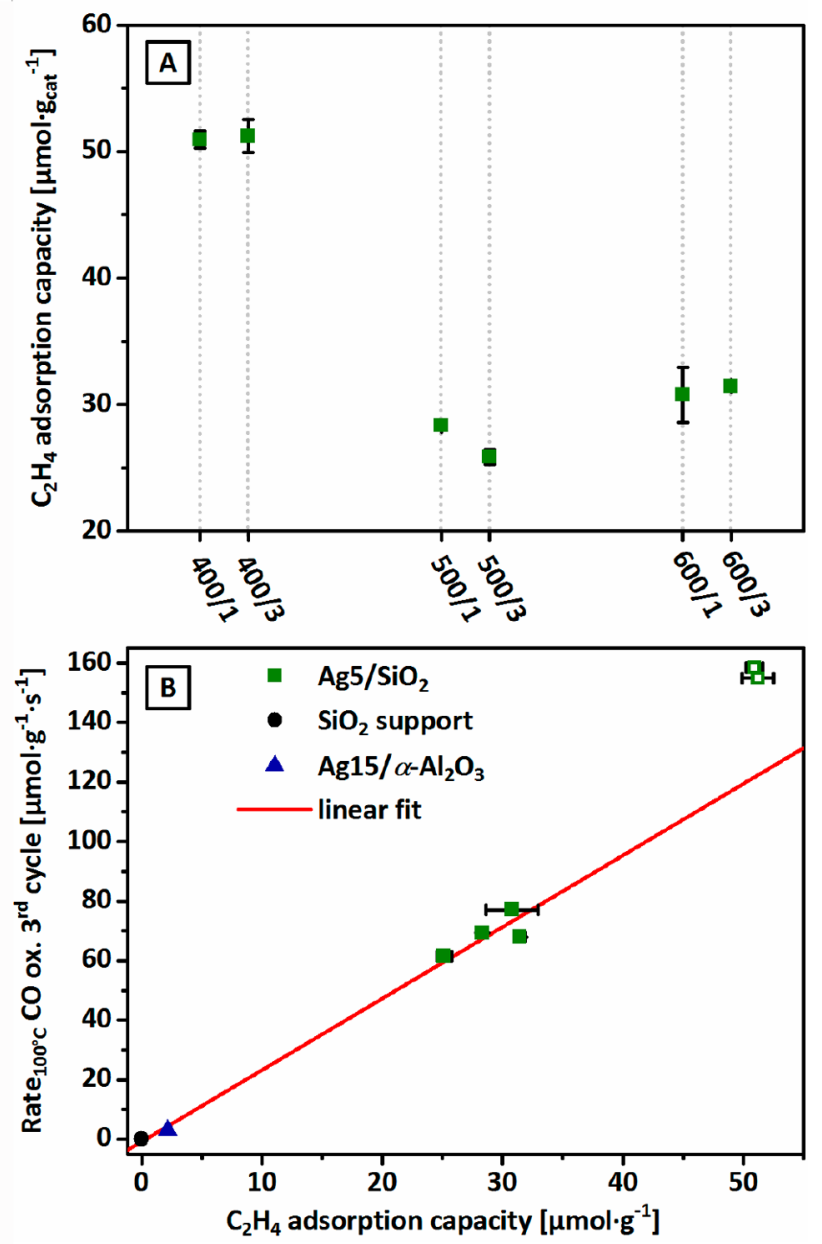

Figure 9. (A) $\mathrm{C}_{2} \mathrm{H}_{4}$ adsorption capacities of $\mathrm{Ag} 5 / \mathrm{SiO}_{2}$ catalysts calcined at 400,500 , and $600{ }^{\circ} \mathrm{C}$ for 1 and $3 \mathrm{~h}$ dwell time and (B) $\mathrm{C}_{2} \mathrm{H}_{4}$ adsorption capacities of $\mathrm{Ag} 5 / \mathrm{SiO}_{2}$ catalysts without clusters (green solid squares) and with in situ cluster formation (green open squares) correlated to the $\mathrm{CO}$ oxidation rate at $100{ }^{\circ} \mathrm{C}$ for the third cycle together with the pure support without $\mathrm{Ag}$ loading (black circle). Additionally, $\mathrm{C}_{2} \mathrm{H}_{4}$ adsorption capacity determined from microcalorimetry is shown for $\mathrm{Ag} 15 / \alpha-\mathrm{Al}_{2} \mathrm{O}_{3}$ (blue triangle). The corresponding linear fit for cluster-free samples is presented as red line with a $R^{2}$ of 0.986 .

at 500 and $600{ }^{\circ} \mathrm{C}$ have a comparable number of adsorption sites for $\mathrm{C}_{2} \mathrm{H}_{4}$. The slightly increased number of adsorption sites for the samples calcined at $600{ }^{\circ} \mathrm{C}$ are in line with PS distribution (Figure 6, Figure S15, and overview in Table 1).

Samples calcined at $400{ }^{\circ} \mathrm{C}$ show a significantly higher $\mathrm{C}_{2} \mathrm{H}_{4}$ adsorption capacity of average $71.7 \mu \mathrm{mol} \cdot \mathrm{g}_{\text {cat }}{ }^{-1}$ for $400 / 0$ and $50.9 \mu \mathrm{mol} \cdot \mathrm{g}_{\text {cat }}{ }^{-1}$ for sample $400 / 1$ and $51.2 \mu \mathrm{mol} \cdot \mathrm{g}_{\text {cat }}{ }^{-1}$ for sample 400/3. For 400/0 the remaining $\mathrm{AgNO}_{3}$ contributed strongly to the high adsorption value. This is also visible in the change from measurement 1 to 3 , namely, the decrease of $\mathrm{C}_{2} \mathrm{H}_{4}$ adsorption capacity from $76.7 \mu \mathrm{mol} \cdot \mathrm{g}_{\text {cat }}{ }^{-1}$ to $70.8 \mu \mathrm{mol}$. $\mathrm{g}_{\text {cat }}{ }^{-1}$ to $67.6 \mu \mathrm{mol} \cdot \mathrm{g}_{\text {cat }}{ }^{-1}$ (Figure S17). This decrease was induced by the thermolysis during the intermediate $230{ }^{\circ} \mathrm{C}$ heat treatment applied for desorbing the $\mathrm{C}_{2} \mathrm{H}_{4}$ between each of the three measurements. It further led to the formation of nanoparticles and clusters which have a smaller number of adsorption sites than atomically dispersed $\mathrm{Ag}^{+}$, thereby decreasing the overall adsorption capacities (in line with the microcalorimetric $\mathrm{C}_{2} \mathrm{H}_{4}$ adsorption). This change is less pronounced for sample $400 / 1$, with only a weak decrease from $51.9 \mu \mathrm{mol} \cdot \mathrm{g}_{\mathrm{cat}}{ }^{-1}$ to $50.6 \mu \mathrm{mol} \cdot \mathrm{g}_{\mathrm{cat}}{ }^{-1}$ and $50.4 \mu \mathrm{mol} \cdot \mathrm{g}_{\mathrm{cat}}{ }^{-1}$, whereas the difference of measurement 2 to 3 is within the measurement error of the setup of approximately $\pm 0.3 \mu \mathrm{mol}$. $\mathrm{g}_{\text {cat }}{ }^{-1}$. Furthermore, samples $400 / 1$ and $400 / 3$ are resulting in the same adsorption capacities, indicating that for sample 400/ 1 no remaining $\mathrm{AgNO}_{3}$ was present for the second and third analyses.

On the basis of the adsorption measurements, an apparent Ag surface is estimated. Under the assumption of a full oxygen coverage of the $\mathrm{Ag}$ surface, it is assumed that one $\mathrm{C}_{2} \mathrm{H}_{4}$ molecule binds to one $\mathrm{Ag}_{2} \mathrm{O}$ site, consequently meaning that one $\mathrm{C}_{2} \mathrm{H}_{4}$ titrates two $\mathrm{Ag}$ atoms. Thereby, we can estimate the number of $\mathrm{Ag}$ atoms present on the surface. Using a covalent radius for $\mathrm{Ag}$ of $144 \mathrm{pm}$, the following $\mathrm{Ag}$ surface areas are calculated based on the number of Ag atoms. The determined adsorption capacities as well as the calculated apparent $\mathrm{Ag}$ surface areas are presented in Table 3.

Table 3. $\mathrm{C}_{2} \mathrm{H}_{4}$ Adsorption Capacities Determined by atmTAP, Corresponding Apparent Ag Surface Areas, and CO Oxidation Rates at $100{ }^{\circ} \mathrm{C}$

$\begin{array}{cccc}\text { sample } & \begin{array}{c}\mathrm{C}_{2} \mathrm{H}_{4} \text { adsorption } \\ \text { capacity } \\ {\left[\mu \mathrm{mol} \cdot \mathrm{g}^{-1}\right]}\end{array} & \begin{array}{c}\mathrm{Ag} \text { surface } \\ \text { area } \\ {\left[\mathrm{m}^{2} \cdot \mathrm{g}^{-1}\right]}\end{array} & \begin{array}{c}\text { rate }_{100}{ }^{\circ} \mathrm{C} \text { CO } \\ \text { oxidation, cycle 3 } \\ {\left[\mu \mathrm{mol} \cdot \mathrm{g}^{-1} \cdot \mathrm{s}^{-1}\right]}\end{array} \\ \mathrm{Ag5} / \mathrm{SiO}_{2} 400 / 1 & 50.9 & 4.00 & 158.3 \\ \mathrm{Ag} 5 / \mathrm{SiO}_{2} 400 / 3 & 51.2 & 4.02 & 154.9 \\ \mathrm{Ag} 5 / \mathrm{SiO}_{2} 500 / 1 & 28.3 & 2.22 & 69.3 \\ \mathrm{Ag} 5 / \mathrm{SiO}_{2} 500 / 3 & 25.9 & 2.03 & 61.6 \\ \mathrm{Ag} 5 / \mathrm{SiO}_{2} 600 / 1 & 30.8 & 2.42 & 77.0 \\ \mathrm{Ag} 5 / \mathrm{SiO}_{2} 600 / 3 & 31.5 & 2.59 & 67.9 \\ \mathrm{Ag} 15 / \alpha-\mathrm{Al}_{2} \mathrm{O}_{3}{ }^{a} & 2.17 & 0.17 & 2.9\end{array}$

${ }^{a}$ Determined by microcalorimetric $\mathrm{C}_{2} \mathrm{H}_{4}$ adsorption.

The Ag15/ $\alpha-\mathrm{Al}_{2} \mathrm{O}_{3}$ reference was measured using surface titration experiments via microcalorimetry, since the surface area values are too small for the atmTAP approach. The $\mathrm{C}_{2} \mathrm{H}_{4}$ adsorption (Figure S18) is determined to $2.17 \mu \mathrm{mol} \cdot \mathrm{g}_{\mathrm{cat}}{ }^{-1}$ and is further compared to the catalytic $\mathrm{CO}$ oxidation performances (see values in Table 2).

As presented in Figure 9B, the calculated $\mathrm{C}_{2} \mathrm{H}_{4}$ adsorption capacities are related to the rate in $\mathrm{CO}$ oxidation at $100{ }^{\circ} \mathrm{C}$ for cycle 3 after a 300/3 pretreatment (identical to the atmTAP measurements). A linear correlation can be drawn for samples up to adsorption capacities of $31 \mu \mathrm{mol} \cdot \mathrm{g}^{-1}$ taking nearby various $\mathrm{Ag} 5 / \mathrm{SiO}_{2}$ samples, also pure $\mathrm{SiO}_{2}$ support and the reference $\mathrm{Ag} 15 / \alpha-\mathrm{Al}_{2} \mathrm{O}_{3}$ sample into account. As discussed above, these samples are free of Ag clusters and therefore have a different $\mathrm{Ag}-\mathrm{O}$ interaction. By comparison of the high $\mathrm{Ag}$ surface area catalysts of around $50 \mu \mathrm{mol} \cdot \mathrm{g}^{-1}$, the linear correlation does not fit. The calculated rate is about $35 \mu \mathrm{mol}$. $\mathrm{g}^{-1} \cdot \mathrm{s}^{-1}$ higher than extrapolated by the linear correlation. Since these samples are prone to form Ag clusters, the discrepancy is explained by the nature of the Ag clusters and also indicated by the irreversible sites for $\mathrm{C}_{2} \mathrm{H}_{4}$ adsorption (Figure 8). Since $\mathrm{CO}$ oxidation is only possible upon activation of oxygen by the catalyst, the $\mathrm{Ag}-\mathrm{O}$ interaction strength is also relevant for $\mathrm{CO}$ oxidation. Therefore, it is reasonable that the linear correlation does not include the Ag clusters dominating the catalysis. This is also visible by a change of reaction orders and finally resulting in a $\mathrm{Ag}$ particle/cluster size effect for the $\mathrm{CO}$ oxidation reaction. 


\section{CONCLUSION}

We report on an improved synthesis approach for a set of $\mathrm{SiO}_{2}$ supported $\mathrm{Ag}$ nanoparticles with a narrow PS distribution and median PS of $\sim 2 \mathrm{~nm}$ based on an advanced incipient wetness impregnation technique. Ag nanoparticles show a high tendency to form $\mathrm{Ag}_{2} \mathrm{CO}_{3}$, as demonstrated by PXRD, which was absent for bulk-like $\mathrm{Ag}$ particles of a $\mathrm{Ag} 15 / \alpha-\mathrm{Al}_{2} \mathrm{O}_{3}$ reference sample. Catalysts $\mathrm{Ag} 5 / \mathrm{SiO}_{2}$, exhibiting solely $\mathrm{Ag}$ nanoparticles and clusters, were highly active in $\mathrm{CO}$ oxidation, after a dedicated pretreatment which is related to the $\mathrm{Ag}_{2} \mathrm{CO}_{3}$ formation. Performing detailed investigations concerning the pretreatment conditions, we were able to demonstrate that $\mathrm{Ag}$ nanoparticles need a significantly harsher pretreatment compared to bulk-like Ag particles (higher temperature and/ or longer dwell times). This pretreatment dependence might also be the reason for differentiated findings in literature concerning Ag nanoparticles and their catalytic performance. Further, Ag clusters were in situ created and showed a significantly higher activity in CO oxidation.

Investigations on the correlation of $\mathrm{Ag}$ PS and the strength of the Ag-O interaction were performed. The formation of high temperature stable oxygen species with a strong $\mathrm{Ag}-\mathrm{O}$ interaction on $\mathrm{Ag}$ nanoparticles and clusters was confirmed by microcalorimetric oxygen and $\mathrm{C}_{2} \mathrm{H}_{4}$ adsorption experiments. The strength of the $\mathrm{Ag}-\mathrm{O}$ interaction was attributed to the higher ionicity of the $\mathrm{Ag}^{\delta+} \mathrm{O}_{x}$ species directly correlating with the tendency of carbonate formation. Especially, the $\mathrm{Ag}$ clusters, also responsible for different reaction orders upon comparison to $\mathrm{Ag}$ nanoparticles, showed, using $\mathrm{C}_{2} \mathrm{H}_{4}$ titration, an in parts irreversible adsorption behavior. This finding supports a PS effect for Ag clusters in $\mathrm{CO}$ oxidation.

A newly introduced method for estimating the available reactive surface area was applied based on the $\mathrm{C}_{2} \mathrm{H}_{4}$ adsorption capacity. Thereby, a linear correlation of the $\mathrm{CO}$ oxidation rate with the $\mathrm{C}_{2} \mathrm{H}_{4}$ adsorption capacity of bulk-like $\mathrm{Ag}$ and $\mathrm{Ag}$ nanoparticles was demonstrated. Ag clusters exhibited a superior $\mathrm{CO}$ oxidation activity compared to nanoparticles and bulk $\mathrm{Ag}$ particles and deviate from the linear correlation, which can be directly attributed to the discussed $\mathrm{Ag}-\mathrm{O}$ interaction and a distinct cluster size effect for $\mathrm{Ag}$ of $<1 \mathrm{~nm}$ in size.

\section{ASSOCIATED CONTENT}

\section{S Supporting Information}

The Supporting Information is available free of charge on the ACS Publications website at DOI: 10.1021/acsanm.9b00344.

Precursor characterization, X-ray diffraction patterns, additional CO oxidation data, electron microscopy, TPR analysis, microcalorimetry, and adsorption measurements (PDF)

\section{AUTHOR INFORMATION}

\section{Corresponding Author}

*E-mail: efrei@fhi-berlin.mpg.de.

\section{ORCID}

Travis Jones: 0000-0001-8921-7641

Elias Frei: 0000-0003-3565-1199

\section{Notes}

The authors declare no competing financial interest.

\section{ACKNOWLEDGMENTS}

We highly appreciate the support of Pierre Kube and Rania Hanna (catalytic testing), Wiebke Frandsen (SEM-EDX), and Jasmin Allan (TGA).

\section{REFERENCES}

(1) Keulks, G. W.; Chang, C. C. Kinetics and mechanism of carbon monoxide oxidation over silver catalysts. J. Phys. Chem. 1970, 74, 2590-2595.

(2) Qian, M.; Liauw, M. A.; Emig, G. Formaldehyde synthesis from methanol over silver catalysts. Appl. Catal., A 2003, 238, 211-222.

(3) Ozbek, M. O.; Onal, I.; van Santen, R. A. Why silver is the unique catalyst for ethylene epoxidation. J. Catal. 2011, 284, 230235.

(4) Lambert, R. M.; Williams, F. J.; Cropley, R. L.; Palermo, A. Heterogeneous alkene epoxidation: past, present and future. J. Mol. Catal. A: Chem. 2005, 228, 27-33.

(5) Bukhtiyarov, V. I.; Prosvirin, I. P.; Kvon, R. I.; Goncharova, S. N.; Bal'zhinimaev, B. S. XPS study of the size effect in ethene epoxidation on supported silver catalysts. J. Chem. Soc., Faraday Trans. 1997, 93, 2323-2329.

(6) Lee, J. K.; Verykios, X. E.; Pitchai, R. Support and crystallite size effects in ethylene oxidation catalysis. Appl. Catal. 1989, 50, 171-188.

(7) Wu, J. C.; Harriott, P. The effect of crystallite size on the activity and selectivity of silver catalysts. J. Catal. 1975, 39, 395-402.

(8) Somorjai, G. A.; Contreras, A. M.; Montano, M.; Rioux, R. M. Clusters, surfaces, and catalysis. Proc. Natl. Acad. Sci. U. S. A. 2006, 103, 10577.

(9) Grunes, J.; Zhu, J.; Somorjai, G. A. Catalysis and nanoscience. Chem. Commun. 2003, 2257-2260.

(10) Tsybulya, S. V.; Kryukova, G. N.; Goncharova, S. N.; Shmakov, A. N.; Balzhinimaev, B. S. Study of the Real Structure of Silver Supported Catalysts of Different Dispersity. J. Catal. 1995, 154, 194200.

(11) Goncharova, S. N.; Paukshtis, E. A.; Bal'zhinimaev, B. S. Size effects in ethylene oxidation on silver catalysts. Influence of support and Cs promoter. Appl. Catal., A 1995, 126, 67-84.

(12) Sajkowski, D. J.; Boudart, M. Structure Sensitivity of the Catalytic Oxidation of Ethene by Silver. Catal. Rev.: Sci. Eng. 1987, 29, 325-360.

(13) Verykios, X. E.; Stein, F. P.; Coughlin, R. W. Influence of metal crystallite size and morphology on selectivity and activity of ethylene oxidation catalyzed by supported silver. J. Catal. 1980, 66, 368-382.

(14) van den Reijen, J. E.; Kanungo, S.; Welling, T. A. J.; VersluijsHelder, M.; Nijhuis, T. A.; de Jong, K. P.; de Jongh, P. E. Preparation and particle size effects of $\mathrm{Ag} / \alpha-\mathrm{Al} 2 \mathrm{O} 3$ catalysts for ethylene epoxidation. J. Catal. 2017, 356, 65-74.

(15) Fotopoulos, A. P.; Triantafyllidis, K. S. Ethylene epoxidation on $\mathrm{Ag}$ catalysts supported on non-porous, microporous and mesoporous silicates. Catal. Today 2007, 127, 148-156.

(16) Lei, Y.; Mehmood, F.; Lee, S.; Greeley, J.; Lee, B.; Seifert, S.; Winans, R. E.; Elam, J. W.; Meyer, R. J.; Redfern, P. C.; Teschner, D.; Schlögl, R.; Pellin, M. J.; Curtiss, L. A.; Vajda, S. Increased Silver Activity for Direct Propylene Epoxidation via Subnanometer Size Effects. Science 2010, 328, 224-228.

(17) Qu, Z.; Huang, W.; Cheng, M.; Bao, X. Restructuring and Redispersion of Silver on $\mathrm{SiO} 2$ under Oxidizing/Reducing Atmospheres and Its Activity toward CO Oxidation. J. Phys. Chem. B 2005, $109,15842-15848$.

(18) Lim, D. C.; Lopez-Salido, I.; Kim, Y. D. Size selectivity for COoxidation of $\mathrm{Ag}$ nanoparticles on highly ordered pyrolytic graphite (HOPG). Surf. Sci. 2005, 598, 96-103.

(19) Campbell, C. T.; Sellers, J. R. V. Anchored metal nanoparticles: Effects of support and size on their energy, sintering resistance and reactivity. Faraday Discuss. 2013, 162, 9-30.

(20) Campbell, C. T. The Energetics of Supported Metal Nanoparticles: Relationships to Sintering Rates and Catalytic Activity. Acc. Chem. Res. 2013, 46, 1712-1719. 
(21) Lefferts, L.; van Ommen, J. G.; Ross, J. R. H. The influence of hydrogen treatment and catalyst morphology on the interaction of oxygen with a silver catalyst. Appl. Catal. 1987, 34, 329-339.

(22) Jones, T. E.; Wyrwich, R.; Böcklein, S.; Rocha, T. C. R.; Carbonio, E. A.; Knop-Gericke, A.; Schlögl, R.; Günther, S.; Wintterlin, J.; Piccinin, S. Oxidation of Ethylene on Oxygen Reconstructed Silver Surfaces. J. Phys. Chem. C 2016, 120, 2863028638 .

(23) Rocha, T. C. R.; Oestereich, A.; Demidov, D. V.; Havecker, M.; Zafeiratos, S.; Weinberg, G.; Bukhtiyarov, V. I.; Knop-Gericke, A.; Schlogl, R. The silver-oxygen system in catalysis: new insights by near ambient pressure X-ray photoelectron spectroscopy. Phys. Chem. Chem. Phys. 2012, 14, 4554-4564.

(24) Rocca, M.; Savio, L.; Vattuone, L.; Burghaus, U.; Palomba, V.; Novelli, N.; Buatier de Mongeot, F.; Valbusa, U.; Gunnella, R.; Comelli, G.; Baraldi, A.; Lizzit, S.; Paolucci, G. Phase transition of dissociatively adsorbed oxygen on $\mathrm{Ag}(001)$. Phys. Rev. B: Condens. Matter Mater. Phys. 2000, 61, 213-227.

(25) Carbonio, E. A.; Rocha, T. C. R.; Klyushin, A. Y.; Pis, I.; Magnano, E.; Nappini, S.; Piccinin, S.; Knop-Gericke, A.; Schlogl, R.; Jones, T. E. Are multiple oxygen species selective in ethylene epoxidation on silver? Chemical Science. 2018, 9, 990-998.

(26) Rovida, G.; Pratesi, F.; Maglietta, M.; Ferroni, E. Chemisorption of oxygen on the silver (111) surface. Surf. Sci. 1974, 43, 230-256.

(27) Herein, D.; Nagy, A.; Schubert, H.; Weinberg, G.; Kitzelmann, E.; Schlögl, R. The Reaction of Molecular Oxygen with Silver at Technical Catalytic Conditions: Bulk Structural Consequences of a Gas-Solid Interface Reaction. Z. Phys. Chem. 1996, 197, 67.

(28) Rocha, T. C. R.; Hävecker, M.; Knop-Gericke, A.; Schlögl, R. Promoters in heterogeneous catalysis: The role of $\mathrm{Cl}$ on ethylene epoxidation over Ag. J. Catal. 2014, 312, 12-16.

(29) Li, W.-X.; Stampfl, C.; Scheffler, M. Why is a Noble Metal Catalytically Active? The Role of the O-Ag Interaction in the Function of Silver as an Oxidation Catalyst. Phys. Rev. Lett. 2003, 90, 256102.

(30) Rehren, C.; Isaac, G.; Schlögl, R.; Ertl, G. Surface and subsurface products of the interaction of $\mathrm{O} 2$ with $\mathrm{Ag}$ under catalytic conditions. Catal. Lett. 1991, 11, 253-265.

(31) Waterhouse, G. I. N.; Bowmaker, G. A.; Metson, J. B. Oxygen chemisorption on an electrolytic silver catalyst: a combined TPD and Raman spectroscopic study. Appl. Surf. Sci. 2003, 214, 36-51.

(32) Schlögl, R. Heterogeneous Catalysis. Angew. Chem., Int. Ed. 2015, 54, 3465-3520.

(33) Schlögl, R.; Abd Hamid, S. B. Nanokatalyse: alter Wein in neuen Schläuchen oder etwas wirklich Neues? Angew. Chem. 2004, 116, 1656-1667.

(34) Harriott, P. The oxidation of ethylene using silver on different supports. J. Catal. 1971, 21, 56-65.

(35) Busca, G. The surface acidity of solid oxides and its characterization by IR spectroscopic methods. An attempt at systematization. Phys. Chem. Chem. Phys. 1999, 1, 723-736.

(36) Rosendahl, T.; Mäurer, T.; Dobner, C. K.; Lehr, A.; Wanka, J. Verfahren zur herstellung eines geträgerten Silberkatalysators. WO Patent WO/2013/061294, 2013.

(37) Liang, X.; Li, J.; Yu, M.; McMurray, C. N.; Falconer, J. L.; Weimer, A. W. Stabilization of Supported Metal Nanoparticles Using an Ultrathin Porous Shell. ACS Catal. 2011, 1, 1162-1165.

(38) Ma, Z.; Dai, S. Stabilizing Gold Nanoparticles by Solid Supports. In Heterogeneous Gold Catalysts and Catalysis; The Royal Society of Chemistry, 2014; Chapter 1, pp 1-26.

(39) Yan, D.; Wang, F.; Zhao, Y.; Liu, J.; Wang, J.; Zhang, L.; Park, K. C.; Endo, M. Production of a high dispersion of silver nanoparticles on surface-functionalized multi-walled carbon nanotubes using an electrostatic technique. Mater. Lett. 2009, 63, 171-173.

(40) Cao, A.; Lu, R.; Veser, G. Stabilizing metal nanoparticles for heterogeneous catalysis. Phys. Chem. Chem. Phys. 2010, 12, 1349913510 .
(41) Farmer, J. A.; Campbell, C. T. Ceria Maintains Smaller Metal Catalyst Particles by Strong Metal-Support Bonding. Science 2010, 329, 933.

(42) Yamamoto, T.; Nagase, S.; Tanabe, H. Silver catalyst for production of ethylene oxide and method for manufacture thereof. U.S. Patent US5077256A, 1991.

(43) Bongaarts, J. E.; Meima, G. R.; Geus, J. W. Silver catalyst and a process for preparing same. U.S. Patent 4,786,743,1988.

(44) Haynes, W. M. CRC Handbook of Chemistry and Physics, 96th ed..; CRC Press, 2015.

(45) Marceau, E.; Carrier, X.; Che, M.; Clause, O.; Marcilly, C. Ion Exchange and Impregnation In Handbook of Heterogeneous Catalysis.; Wiley-VCH Verlag GmbH \& Co. KGaA, 2008.

(46) Yang, H.; Ma, C.; Zhang, X.; Li, Y.; Cheng, J.; Hao, Z. Understanding the Active Sites of $\mathrm{Ag} /$ Zeolites and Deactivation Mechanism of Ethylene Catalytic Oxidation at Room Temperature. ACS Catal. 2018, 8, 1248-1258.

(47) Freund, H.-J.; Meijer, G.; Scheffler, M.; Schlögl, R.; Wolf, M. CO Oxidation as a Prototypical Reaction for Heterogeneous Processes. Angew. Chem., Int. Ed. 2011, 50, 10064-10094.

(48) Coelho, A. TOPAS: General Profile and Structure Analysis Software for Powder Diffraction Data, version 5; Bruker AXS GmbH: Karlsruhe, Germany, 2014.

(49) Brunauer, S.; Emmett, P. H.; Teller, E. Adsorption of Gases in Multimolecular Layers. J. Am. Chem. Soc. 1938, 60, 309-319.

(50) Scharfenberg, L.; Horn, R. Temporal Analysis of Products Experiments at Atmospheric Pressure: The Epoxidation of Ethylene on Silver. Chem. Ing. Tech. 2017, 89, 1350-1359.

(51) Chichagov, A. V.; Belonozhko, A. B.; Lopatin, A. L.; Dokina, T. N.; Samokhvalova, O. L.; Ushakovskaya, T. V.; Shilova, Z. V. Kristallografiya 1990, 35, 610-616.

(52) Qu, Z.; Cheng, M.; Huang, W.; Bao, X. Formation of subsurface oxygen species and its high activity toward $\mathrm{CO}$ oxidation over silver catalysts. J. Catal. 2005, 229, 446-458.

(53) Jette, E. R.; Foote, F. Precision Determination of Lattice Constants. J. Chem. Phys. 1935, 3, 605-616.

(54) Koga, N.; Yamada, S.; Kimura, T. Thermal Decomposition of Silver Carbonate: Phenomenology and Physicogeometrical Kinetics. J. Phys. Chem. C 2013, 117, 326-336.

(55) Luo, W.; Hu, W.; Xiao, S. Size Effect on the Thermodynamic Properties of Silver Nanoparticles. J. Phys. Chem. C 2008, 112, 23592369.

(56) Bao, X.; Muhler, M.; Schedel-Niedrig, T.; Schlögl, R. Interaction of oxygen with silver at high temperature and atmospheric pressure: A spectroscopic and structural analysis of a strongly bound surface species. Phys. Rev. B: Condens. Matter Mater. Phys. 1996, 54, $2249-2262$.

(57) Bukhtiyarov, V. I.; Knop-Gericke, A. Ethylene Epoxidation over Silver Catalysts. In Nanostructured Catalysts: Selective Oxidations; The Royal Society of Chemistry: Cambridge, U.K., 2011; Chapter 9, pp 214-247; DOI: 10.1039/9781847559876-00214.

(58) Solomon, J. L.; Madix, R. J.; Stohr, J. Orientation of ethylene and propylene on $\operatorname{Ag}(110)$ from near edge $x$-ray adsorption fine structure. J. Chem. Phys. 1990, 93, 8379-8382.

(59) Scholten, J. J. F.; Konvalinka, J. A.; Beekman, F. W. Reaction of nitrous oxide and oxygen with silver surfaces, and application to the determination of free-silver surface areas of catalysts. J. Catal. 1973, $28,209-220$

(60) Chinchen, G. C.; Hay, C. M.; Vandervell, H. D.; Waugh, K. C. The measurement of copper surface areas by reactive frontal chromatography. J. Catal. 1987, 103, 79-86.

(61) Vannice, M. A. Kinetics of Catalytic Reactions; Springer, 2005; pp $1-240$. 